\title{
Mindfulness-Based Programs in the Workplace: a Meta-Analysis of Randomized Controlled Trials
}

\author{
Ruben Vonderlin $^{1}$ (D) Miriam Biermann ${ }^{1} \cdot$ Martin Bohus $^{1,2} \cdot$ Lisa Lyssenko $^{3}$
}

Published online: 2 March 2020

(C) The Author(s) 2020

\begin{abstract}
Objectives Given the complex demands of many workplaces, there is growing interest in the potential beneficial effects of mindfulness-based programs (MBPs) for employees. This meta-analysis systematically synthesizes the results of randomized controlled studies conducted in various workplace settings.

Methods Eligible studies were identified by a systematic literature search in four electronic databases and complementary manual search strategies through 11/2018. Random-effects models were used to synthesize data across 56 studies including $n=2689$ participants and $n=2472$ controls. The validity of synthesized effect size estimates was analyzed for heterogeneity and influential cases (outliers). Risk of bias was assessed following Cochrane recommendations.

Results Analyses of between-group effects indicated that MBPs effectively reduce stress, burnout, mental distress, and somatic complaints, while improving mindfulness, well-being, compassion, and job satisfaction — all with small to large effect sizes ranging from Hedge's $g=0.32$ to 0.77 . Results were maintained in follow-up assessments $\leq 12$ weeks. Heterogeneity among primary studies was not explained consistently by program or participant characteristics in the exploratory moderator analyses. Results on work engagement and productivity were limited by low numbers of primary studies with outliers among their effect sizes.

Conclusions Our meta-analysis provides evidence that MBPs effectively promote the health and well-being of employees in various occupational settings. Further research is needed to investigate potential benefits on work-related outcomes and effects for longer-term follow-ups.
\end{abstract}

Keywords Meta-analysis $\cdot$ Mindfulness-based programs $\cdot$ Workplace randomized controlled trials

Globalization, digitization, and societal transformations have changed the world of work dramatically in the last decades: work processes have become more complex, more intense, and require more flexibility and mobility from employees

Electronic supplementary material The online version of this article (https://doi.org/10.1007/s12671-020-01328-3) contains supplementary material, which is available to authorized users.

Ruben Vonderlin

ruben.vonderlin@zi-mannheim.de

1 Institute for Psychiatric and Psychosomatic Psychotherapy, Central Institute of Mental Health, Heidelberg University, J5, 68159 Mannheim, Germany

2 McLain Hospital, Harvard Medical School, Boston, MA, USA

3 Department of Public Health and Health Education, University of Education, Freiburg, Germany
(Mack et al. 2015). Productivity per hour worked has increased by approximately $20 \%$ since the year 2000 across OECD countries (OECD 2018). Adverse effects of the increased psychosocial demands include prolonged workrelated stress, exhaustion, burnout, and subsequent health impairments (Quick and Henderson 2016). Absenteeism and presenteeism account for major productivity losses and high societal costs in industrialized countries (Schmidt et al. 2019; Strömberg et al. 2017). Consequently, health promotion has become an important objective in occupational settings.

Mindfulness-based programs (MBPs) have attained an outstanding position among occupational health promotion programs. The proposed benefits go beyond personal well-being to cover key aspects of workplace functioning (e.g., Hülsheger et al. 2013). Both components of mindfulness, as defined by Bishop et al. (2004), have been discussed with regard to their potential for work performance (Good et al. 2016; Hyland et al. 2015). The self-regulation of attention to the present 
moment is thought to enable individuals to better focus on the tasks at hand, be less distractible to extraneous stimuli and avoid mistakes (e.g., Glomb et al. 2011; Good et al. 2016). Relating to one's experiences with curiosity, openness and acceptance has been proposed to spark creativity, open new perspectives, enhance problem-solving, and facilitate coping with uncertainty (Baas et al. 2014; Jacobs and Blustein 2008; Lebuda et al. 2016; Ostafin and Kassman 2012). These intrapersonal qualities might positively affect interpersonal functioning (Moll et al. 2015) and leadership behavior (Nübold et al. 2019; Reb et al. 2019; Schuh et al. 2019). Thus, workplace mindfulness is expected to improve not only individual well-being and performance but also the productivity, agility, and innovative strength of organizations on the whole (Greiser and Martini 2018).

Building on enthusiastic reports from pioneering companies since the late 1980s, an exponential growth in popularity sparked in the 2000s, when a number of large companies launched mindfulness programs for their workforces - the most influential Google, General Mills, Intel, and Target (Gelles 2015; Schaufenbuel 2015). Meanwhile, the provision of services related to mindfulness and/or meditation has become a billion-dollar industry (Wolever et al. 2018). In a survey conducted by the National Business Group on Health (USA) in 2018, about 60\% mid- to large-sized US companies reported offering mindfulness, yoga, or meditation courses to their employees (NBGH 2019). Prominent examples cover a wide range of industries, such as hard- and software development (e.g., Microsoft, Apple, Cisco, SAP), social media (e.g., Facebook, LinkedIn, Twitter), long-established industrial companies (e.g., Beiersdorf, Bosch), clothing and furniture (e.g., Nike, IKEA), global service providers in finance/ insurance (e.g., Aetna, Goldman Sachs), and political institutions (e.g., UK Parliament, US House of Representatives) and numerous programs in health care and educational settings (Burton et al. 2017; Klingbeil and Renshaw 2018).

Interestingly, this large-scale implementation has progressed without sound empirical evidence for the anticipated effects on work-related outcomes (Jamieson and Tuckey 2017). Several scientists have provided a logically stringent theoretical rationale on how empirical findings from other contexts might apply to work performance and productivity (e.g., Good et al. 2016; Hyland et al. 2015). However, the proposed correlates of mindfulness were predominantly investigated in cross-sectional studies (Mesmer-Magnus et al. 2017), thus not allowing inferences, whether similar effects can be achieved through training.

Intervention studies in other settings have shown that mindfulness training provides a variety of benefits by inducing positive changes in attention, cognition, emotions, behavior, and physiology (Hendriks et al. 2017; Jayawardene et al. 2017; Khoury et al. 2015; Spijkerman et al. 2016). However, it has been questioned whether these results can be transferred to occupational settings (Jamieson and Tuckey 2017). Several contextual characteristics may influence the acceptability and potential benefits of MBPs, including working conditions, organizational culture, social norms, and work patterns in specific industries or professions (Glomb et al. 2011; Sutcliffe et al. 2016).

The strong interest in MBPs in workplace settings is reflected by a growing number of systematic reviews. Qualitative reviews have provided an overview of empirical studies across occupational groups (Eby et al. 2019; Jamieson and Tuckey 2017; Janssen et al. 2018; Lomas et al. 2017a) and in specific settings, such as teaching/education (Hwang et al. 2017; Lomas et al. 2017b), health care (Boellinghaus et al. 2014; Escuriex and Labbé 2011; Irving et al. 2009; Lomas et al. 2018; Luken and Sammons 2016; Morgan et al. 2015; Rudaz et al. 2017; Smith 2014), social workers (Trowbridge and Mische Lawson 2016), and managers (Donaldson-Feilder et al. 2019). Although most authors draw encouraging conclusion, the inclusion of uncontrolled studies with a varying methodological quality impede the evaluation to which extent effects can be achieved.

Most previous meta-analyses either refer to a specific occupational group, such as teachers (Iancu et al. 2017; Klingbeil and Renshaw 2018) and mental health professionals (Barns 2017; Burton et al. 2017; Lomas et al. 2018), or to specific outcome variables, e.g., psychological distress (Slemp et al. 2019; Virgili 2015) or burnout (Iancu et al. 2017; Slemp et al. 2019). Two recently published metaanalyses allow a more comprehensive assessment of empirical effectiveness by reporting synthesized effect sizes based on randomized controlled trials (RCTs) published before January 2016 ( $k=35$; Lomas et al. 2019) and May 2016, respectively $(k=23$; Bartlett et al. 2019). However, the exponential increase in popularity also seems to apply to intervention research, as the number of published RCTs has almost doubled between 2016 and 2019. The primary objective of this meta-analysis is, therefore, to update the aforementioned meta-analyses and to extend their work by synthesizing effect sizes on work-related outcomes and long-term effects of MBPs in the occupational setting. The secondary objective is to explore characteristics that may influence the magnitude of effects on different outcome domains.

Several authors have emphasized the large variability across MBPs and the associated difficulties to evaluate their efficacy (e.g., Van Dam et al. 2018). Most empirical research in healthy populations has been conducted on the "classical" manualized form of Mindfulness-Based Stress Reduction (MBSR; Kabat-Zinn 1990; Khoury et al. 2015), but a variety of other multicomponent programs have been designed, combining basic meditation practices with yoga exercises, informal mindfulness techniques and elements of compassion. In workplace settings, the variability of MBPs seems to be even larger (Jamieson and Tuckey 2017). To consider the needs of 
employees and organizations, a variety of modifications have been made to manualized MBPs, such as shortened versions of MBSR (e.g., Huang et al. 2015; Klatt et al. 2009; Manotas et al. 2014) and several idiosyncratic curricula have been developed, which couple mindfulness elements with other training, such as emotion regulation, compassion, or physical exercise to produce beneficial synergistic effects (e.g., Jennings et al. 2013) .

These modified MBPs differ largely in time scope and mode of delivery - all of which might impact their effects on outcomes (Jamieson and Tuckey 2017). Across contexts, brief mindfulness training programs and digital interventions have become increasingly popular due to their advantages in accessibility and availability (Mrazek et al. 2019; Schumer et al. 2018). In the occupational settings, some programs keep to the in-class group format, some use blended curricula combining classroom learning with online practices or e-coaching (Allexandre et al. 2016; van Berkel et al. 2014), while others are delivered exclusively through the internet (Aikens et al. 2014; Wolever et al. 2012). The location of delivery might intensify or diminish contextual influences, e.g., due to implicit associations of office buildings with occupational stress experiences. To account for this variability, we examined possible moderating effects of delivery mode and location, type of program, time scope/duration, and recommended practice at home.

Most empirical studies in occupational settings focus on specific professions, and thus include samples with distributions of participant characteristics different from those in general health promotion. Previous meta-analyses in healthy populations have noted to a preponderance of young female participants in MBP studies (Khoury et al. 2015; Spijkerman et al. 2016), which aligns with general research on the utilization of preventive health care (Dryden et al. 2012; Koopmans et al. 2012). Occupational settings might be an opportunity to reach more diverse populations, possibly including more males and/or older participants (e.g., Martin et al. 2009). Thereby, specific occupational demands and characteristics of professional groups have to be considered (Good et al. 2016). Health care professionals for instance seem to be a logical target group for MBPs due to their exposure to high interpersonal demands and physical stress (Burton et al. 2017). At the same time, this group of professionals might be particularly inclined to cultivating mindfulness skills (Irving et al. 2009). A less favorable climate might prevail in the context of "tough, male"-oriented occupations, such as police officers or firefighters, including social norms, attitudes, and expectations that possibly lower the acceptance and effects of MBPs (see e.g., Krick and Felfe 2019). Other implicit features of samples can include the level of education required to practice a profession or work experience aligned with certain hierarchical positions. To investigate possible influences of these characteristics, we conducted moderator analyses on age, gender, professional group, level of education, and work experience.

\section{Method}

This meta-analysis was conducted according to the PRISMAguidelines (Moher et al. 2009; see PRISMA-checklist in Appendix E in the supplemental materials) and the Cochrane recommendations for the reduction of subjectivity biases and data extraction errors (Higgins et al. 2011). Accordingly, all process steps involving decision-making (e.g., abstract and full-text screening), manual transfer of data (e.g., extraction of data from original studies), or evaluation (e.g., risk-of-bias assessment, clustering primary outcomes to review outcomes) were performed by two reviewers independently, based on standardized coding schemes. Conflicts were discussed and resolved in the reviewer team. A protocol for this metaanalysis was pre-registered and is available in PROSPERO (CRD42015019282).

\section{Literature Search}

We conducted a systematic literature search up to November 2018 in the databases PsychInfo, PubMed, Web of Science, and Academic Search Premier based on the following search strategy: (((DE “Intervention") OR (DE "Prevention") OR (DE "Clinical Trials" OR DE "Treatment Effectiveness Evaluation"))) AND ((DE “Mindfulness") OR mindful* OR (DE "Meditation") OR meditat*) AND (work* OR (DE “Occupational Health") OR (DE “Occupational Stress") OR job). Reference lists of the included studies were screened for relevant literature, and authors were contacted for unpublished and/or incomplete data.

\section{Study Selection}

First, abstracts of all results were screened for eligibility criteria: (a) the reporting of empirical data, (b) mindfulnessbased program, and (c) not explicitly conducted in a setting other than the workplace. Second, full texts of eligible studies were assessed for the inclusion criteria: (1) sample of healthy adults (age 18-65 years) with close to full-time employment (>30 h/week), (2) any type of mindfulness/meditation-based intervention with at least $2 \mathrm{~h}$ of training and with mindfulness elements constituting at least $50 \%$ of the program, (3) programs offered at the workplace or initiated by the employer, (4) randomized control trial design, (5) report of mean $(M)$, standard deviation $(S D)$, and sample size $(N)$ for all relevant outcome measures, or (6) sufficient information to calculate those values. Studies were excluded if they could neither be obtained via electronic access, interlibrary loan, or contact with the authors (Fig. 1). 


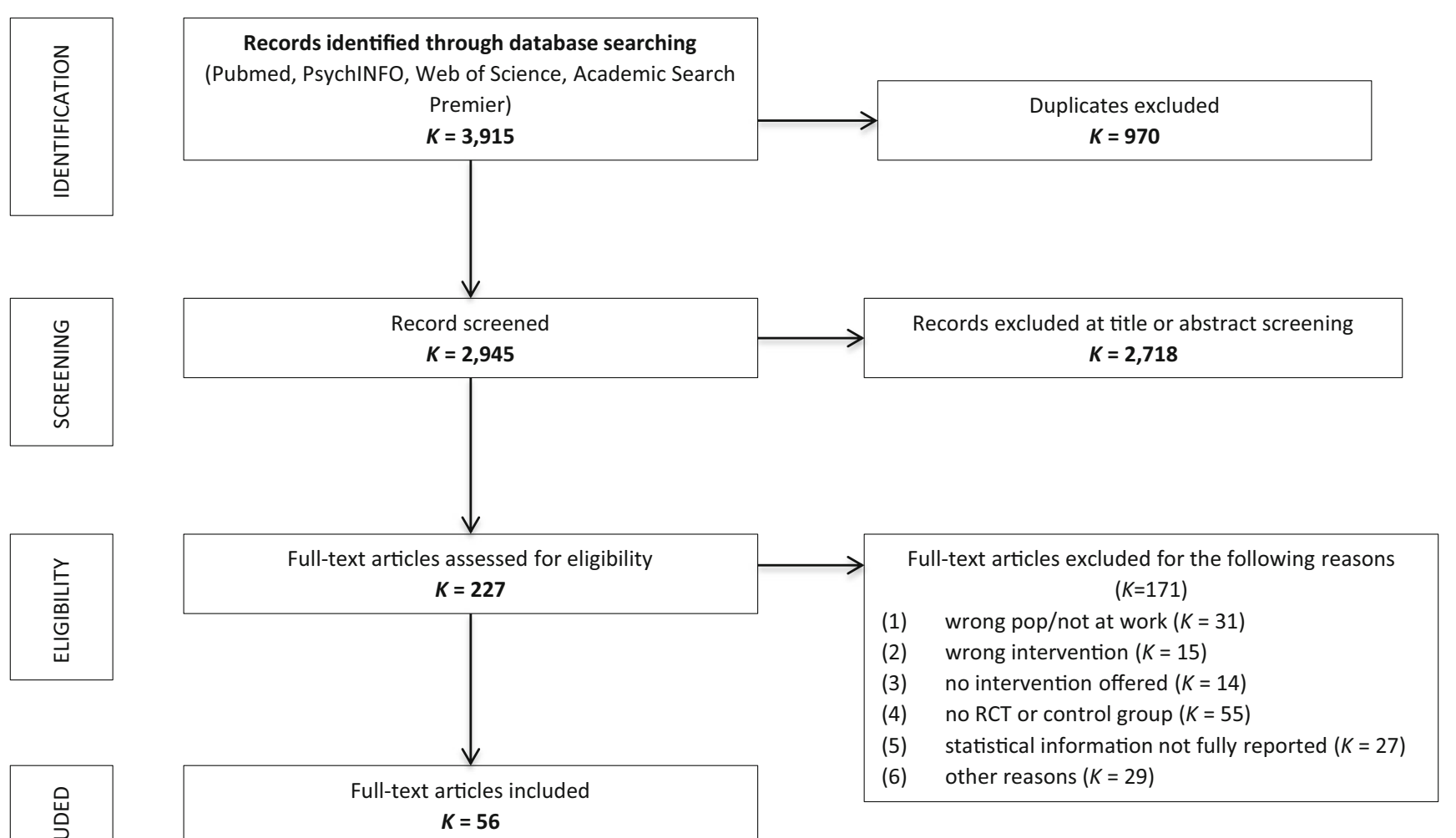

Fig. 1 PRISMA flow diagram (Moher et al. 2009)

\section{Coding of Study Characteristics}

The following characteristics were coded for each included study:

\section{Setting}

Country and organization/corporation in which the study was conducted.

\section{Population}

Age, gender ( $\%$ of female participants), education in years, and work experience. The occupational profession was assigned to the categories of health care, public administration, law enforcement, industry, science, teaching, finance, marketing, phone service (call center), or mixed profession.

\section{Program}

Hours of attendance, time span in weeks, delivery method (i.e. in class, online, blended, audio), and location of delivery (at work, after work, centralized [employees from several organizations meet in a location outside from work], or not specified), and practice time at home. The type of treatment was assigned to the following categories: (a) mindfulness training
(MT) with yoga, (b) MT with relaxation, (c) MT with psychoeducation and personal reflection, (d) MBSR (original and adapted scripts), (e) meditation practice, (f) MT with elements of ACT and/or MBCT, and (g) others.

\section{Methodological Design}

Binary codes were assigned on the handling of missing data via intention-to-treat (ITT) methods, the type of control group (wait-list, active, passive), and the length of the follow-up period ( $\leq 12$ weeks or $>12$ weeks after post-assessment).

\section{Outcome Assessment}

Primary outcome data were clustered by assigning originally reported constructs to review outcomes within the domains of (a) mindfulness, (b) stress and health impairments (perceived stress, subsyndromal symptoms, burnout, somatization \& physical illness), (c) well-being (well-being/life satisfaction, compassion), (d) work-related outcomes (work engagement, productivity, job satisfaction), and (e) resilience (Table 1). Constructs that were assessed in less than four distinct intervention samples were excluded from analyses, i.e., aggression, job control, job security, self-esteem, and empathy. If a study reported more than one measure per review outcome, we controlled for dependencies by computing the weighted 
mean and pooled standard deviation (according to Cohen (1988), presented in Eqs. (1) and (2)).

$$
\begin{aligned}
M_{\text {pooled }} & =\frac{M_{1} * n_{1}+M_{2} * n_{2}}{n_{1}+n_{2}} \\
\mathrm{SD}_{\text {pooled }} & =\sqrt{\frac{\left(n_{1}-1\right) * S D_{1}^{2}+\left(n_{2}-1\right) * \mathrm{SD}_{2}^{2}}{n_{1}+n_{2}-2}}
\end{aligned}
$$

\section{Computation of Effect Sizes}

As a dependent variable, we computed the standardized mean difference scores between the intervention and control groups (Hedges' $g=\left[\mathrm{m}_{\text {Mindfulness Group }}-\mathrm{m}_{\text {Control Group }}\right] / \mathrm{sd}_{\text {pooled }}$ ). For each review outcome and each time point of assessment (postintervention, follow-up), a g-score was built, with higher values indicating higher scores in the intervention groups (conventions for interpretation: $g=0.2$ small effect, $g=0.5$ medium effect, $g=$ 0.8 large effect; Hedges and Olkin 1985). To account for the high heterogeneity of endpoints within each outcome, we used random-effects models to synthesize g-scores (Raudenbush 1994). The variability in effect size estimates was estimated using the restricted maximum likelihood estimator (REML; Viechtbauer 2005). For sensitivity analyses, influential case diagnostics were computed using Cook's distances (Viechtbauer and Cheung 2010). If applicable, additional analyses without the outliers were performed for comparison.

Heterogeneity was assessed using the index $I^{2}$ (Higgins and Thompson 2002) and tested with Cochran's Q statistic (Cochran 1954), as recommended by the Cochrane Collaboration (Higgins and Green 2008). The $I^{2}$ is a descriptive measure that displays the proportion of total variability, which can be attributed to heterogeneity among the true effects (Viechtbauer 2010). The conventions for interpretation are $I^{2}=25 \%$ small, $I^{2}=50 \%$ medium, and $I^{2}=75 \%$ high heterogeneity (Higgins et al. 2003). Exploratory moderator analyses were conducted on review outcomes indicating a moderate to high degree of heterogeneity if $\geq 10$ primary effect sizes were available (as recommended by Pincus et al. 2011). Categorical moderators were investigated using subgroup analyses (e.g., profession) and continuous moderators via meta-regression (e.g., age). All statistical analyses were performed with $\mathrm{R}$ version 3.2.4 (R Development Core Team 2016) using the metafor package (Viechtbauer 2010).

\section{Risk of Bias}

Funnel plots were graphed for the visual inspection of publication bias. Statistical analysis of funnel plot asymmetry was conducted with Egger's regression test (Egger et al. 1997; Sterne et al. 2005). Primary studies were rated with the Cochrane Collaboration's tool for assessing the risk of bias
Table 1 Development of review outcomes and theoretical domains deducted from originals reported constructs and questionnaires from

\begin{tabular}{|c|c|c|}
\hline Domain & Review outcome & Original reported constructs \\
\hline Mindfulness & Mindfulness & Mindfulness \\
\hline \multirow[t]{2}{*}{ Mental well-being } & $\begin{array}{l}\text { Well-being and life } \\
\text { satisfaction }\end{array}$ & $\begin{array}{l}\text { (Psychological) Well-being } \\
\text { Life satisfaction } \\
\text { Quality of life } \\
\text { Orientation to life } \\
\text { Relaxation disposition } \\
\text { Vigor } \\
\text { Positive affect }\end{array}$ \\
\hline & Compassion & $\begin{array}{l}\text { Self-compassion } \\
\text { Occupational self-compassion } \\
\text { Compassion for others }\end{array}$ \\
\hline \multirow[t]{4}{*}{$\begin{array}{l}\text { Stress and health } \\
\text { impairment }\end{array}$} & Stress & $\begin{array}{l}\text { (Job) stress } \\
\text { (Job) stressors } \\
\text { (Job) Demands } \\
\text { Traumatic stress } \\
\text { Need for recovery } \\
\text { (Job) Strain } \\
\text { Work family conflict } \\
\text { Work home interaction } \\
\text { Work life conflict }\end{array}$ \\
\hline & $\begin{array}{l}\text { Subsyndromal } \\
\text { symptoms }\end{array}$ & $\begin{array}{l}\text { Anxiety } \\
\text { Psychological distress } \\
\text { Depression } \\
\text { Sleep quality/impairment } \\
\text { (Job) Rumination } \\
\text { (Job) Fatique } \\
\text { Negative affect } \\
\text { Worry } \\
\text { Alcohol abuse } \\
\text { Suicidal ideation }\end{array}$ \\
\hline & Burnout & $\begin{array}{l}\text { Emotional exhaustion } \\
\text { Depersonalization } \\
\text { Personal accomplishment } \\
\text { Distancing from work } \\
\text { Personal burnout } \\
\text { Work-related burnout } \\
\text { Client related burnout } \\
\text { Global burnout }\end{array}$ \\
\hline & $\begin{array}{l}\text { Somatization and } \\
\text { physical illness }\end{array}$ & $\begin{array}{l}\text { Physical symptoms } \\
\text { Somatization } \\
\text { Somatic health }\end{array}$ \\
\hline \multirow[t]{3}{*}{$\begin{array}{c}\text { Work-related } \\
\text { outcomes }\end{array}$} & Work engagement & $\begin{array}{l}\text { Vigor for work } \\
\text { Work Engagement }\end{array}$ \\
\hline & Productivity & $\begin{array}{l}\text { Health-related lost days total } \\
\text { Work performance } \\
\text { Cognitive failure } \\
\text { Errors } \\
\text { Productivity loss } \\
\text { Phone calls (call center) }\end{array}$ \\
\hline & Job Satisfaction & $\begin{array}{l}\text { Job satisfaction } \\
\text { Work life satisfaction }\end{array}$ \\
\hline Resilience & Resilience & Resilience \\
\hline
\end{tabular}
primary studies

in randomized trials (Higgins et al. 2011) on the following domains: sequence generation, allocation concealment, incomplete outcome data, and selective outcome reporting. The domain "blinding of participants, personnel, and outcome assessors" was excluded, as blinding is not applicable in studies evaluating psychosocial interventions. 


\section{Results}

The systematic search in the electronic databases yielded $K=$ 3915 articles (Fig. 1). Duplicates were removed $(k=970)$, and 2718 studies were excluded during the abstract screening. Reasons for exclusion in the full-text screening $(k=171)$ were (1) other population $(k=31)$, (2) other intervention $(k=15)$, (3) no intervention offered $(k=14)$, (4) no randomized control trial or control group $(k=55),(5)$ statistical information not fully reported $(k=27)$, or $(6)$ other reasons $(k=29)$. In total, $K=56$ articles were included, reporting data from $k=53$ studies with $i=57$ independent intervention samples (see Table 2 and Appendix A for study descriptions).

\section{Characteristics of Primary Studies}

The primary studies covered a broad range of programs offered in different settings for a variety of occupational groups. The program types most frequently investigated were MBSR (32\%), followed by MT combined with yoga (16\%), MT with elements of ACT and/or MBCT (16\%), and meditation practice $(14 \%)$. On average, the programs involved $16.9 \mathrm{~h}$ of attendance $(S D=12.6)$ and were offered over a period of 1 to 16 weeks, with an average time span of 7.5 weeks $(S D=3.3)$. Most programs were delivered in-class $(i=45,79 \%)$, followed by online programs $(i=7)$, combinations of online and inclass elements $(i=4$; blended), or via audio records $(i=1)$. The most frequent location was the workplace $(i=39,68 \%)$; only few programs were offered off-site $(i=4)$ or after work $(i=2)$. Location of delivery was not explicitly reported for $i=$ 12 programs. Home practices were recommended in all programs, for which information on this coding category was reported $(i=48,84 \%)$.

Overall, the primary studies included 5161 participants, of which 2689 were enrolled in MBPs and 2472 were assigned to control groups. Participants were between 19.5 and 50.5 years old $(m=40.13, S D=7.00, k=46)$ and had an average level of education roughly corresponding to a Bachelor's degree ( $m=$ 15.45 years of education, $S D=0.86 ; k=16)$. On average, the samples included $73 \%$ women $(k=50)$ and differed largely with regard to participant's work experience, ranging from nursing students just starting their professional education (Song and Lindquist 2015) to health care professionals with an average of 24 years of experience $(m=11.51, S D=6.50, k=20)$.

Most of the 53 studies investigated health care employees $(k=19,36 \%)$, followed by teachers $(k=9,17 \%)$ and employees in the industrial $(k=4)$ and finance sector $(k=3)$. Two studies each were conducted in public administration and call centers; one study each in science, law enforcement, and marketing. In 11 studies $(21 \%)$, the MBP was offered to all employees within an organization, irrespective of professional groups. About onethird of the studies were conducted in the USA $(k=22,42 \%)$, followed by the UK $(k=4,8 \%)$ and Spain $(k=4,8 \%)$. The remaining studies were performed in a variety of countries across the globe: three studies each in Canada and Australia; two studies each in the Netherlands, India, China, Poland; one study each in Germany, Taiwan, Denmark, Columbia, South Korea, Luxembourg, Brazil, and New Zealand.

In their study design, $79 \%$ of the studies compared intervention effects to passive control or wait-list control groups $(k=42)$. ITT methods were reported to analyze data in less than half of the studies $(k=21,40 \%)$. Follow-up data up for a period up to 12 weeks after post-measurement was reported in 18 studies (34\%), with a mean time lag of 9.11 weeks $(S D=$ 3.58). Only seven studies (13\%) included longer follow-up periods, ranging from 16 weeks to 3 years $(m=46.12, S D=$ 48.91), of which two did not report between-group effect sizes because the wait-list controls had participated in the program by the time of follow-up assessment. Consequently, none of the review outcomes contained sufficient data for a metaanalytical synthesis of longer follow-up periods.

\section{Meta-Analytical Synthesis and Sensitivity Analyses of Effects}

The meta-analyses of post-intervention effects yielded significant effects in the intended direction across all review outcomes (Table 3, forest plots and funnel plots are presented in Appendix B). The number of primary effect sizes contained in the respective syntheses varied widely, ranging from $k=43$ studies reporting on perceived stress, to $k=4$ on resilience. The programs significantly raised the mindfulness of participants $(g=$ $0.44, p<.001 ; k=32$ ), but strongest effects resulted for the more distal outcomes well-being/life satisfaction $(g=0.68, p=.002$; $k=22)$ and perceived stress $(g=-0.66, p<.001 ; k=43)$. Work-related effects were assessed in comparatively few studies, yet showing significant changes in work engagement $(g=0.53$, $p=.022 ; k=5)$, job satisfaction $(g=0.48, p=.021, k=7)$, and productivity $(g=0.35, p=.036, k=9)$.

Sensitivity analyses of post-intervention effects revealed influential cases (outliers) in all outcome categories, except for mindfulness and compassion (outlier analyses are presented in Appendix B). After the exclusion of outliers, results still indicated significant between-group differences for all outcomes in the domains mental well-being and stress/health impairment, with effect sizes decreasing within a range of 0.07 (stress and burnout) to 0.17 (well-being/life satisfaction). Among workrelated outcomes, only the effect on job satisfaction remained significant in the amended analyses. The positive effect size for productivity dropped considerably in strength and below the level of significance $(g=0.15, p=.061, k=8)$ after removing the outlier, a study on meditation awareness training in a sample of office-based middle-hierarchy managers (Shonin et al. 2014). For resilience and work engagement, no amended analyses were conducted, because less than four studies remained after the exclusion of outliers. 


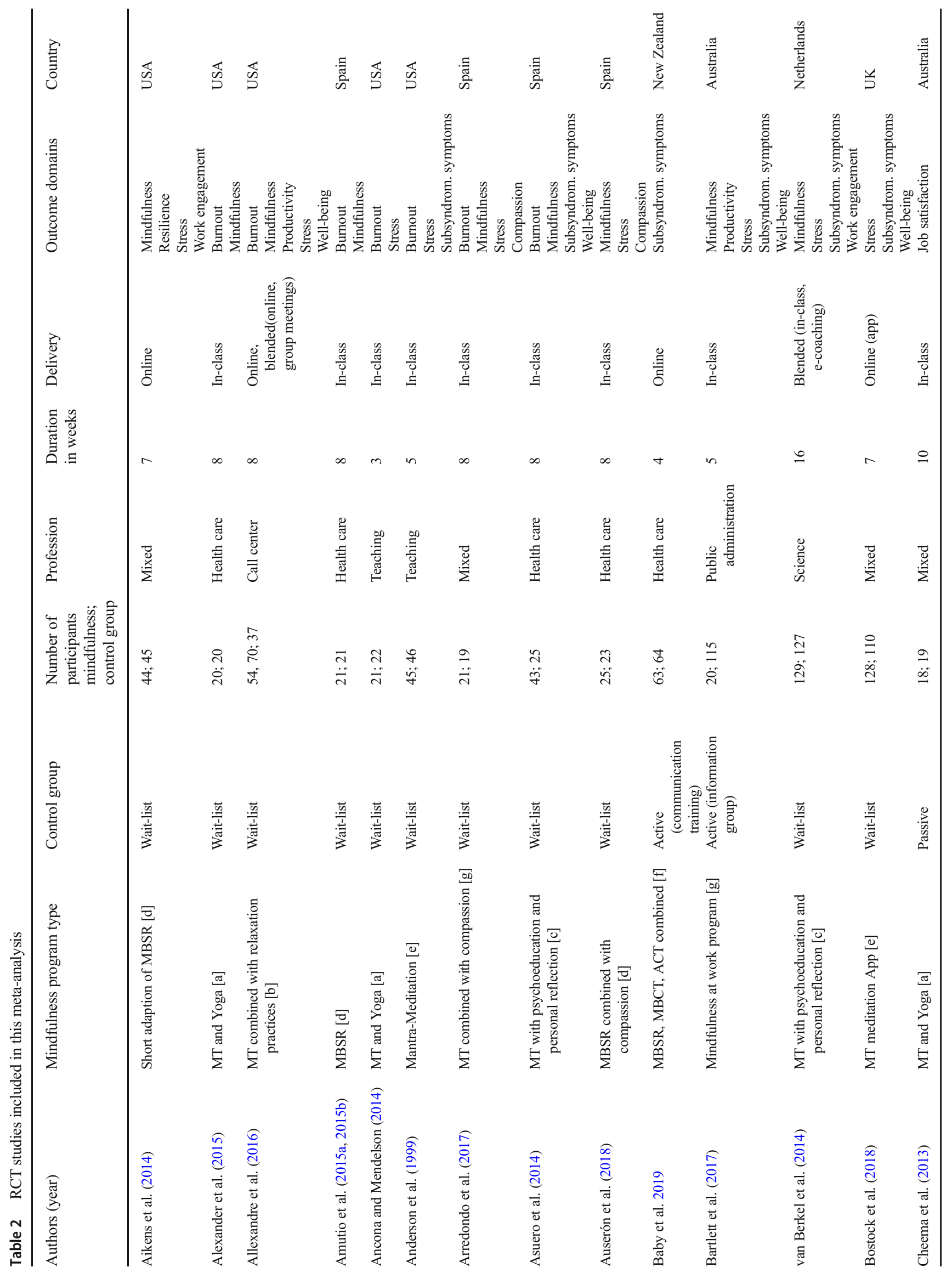




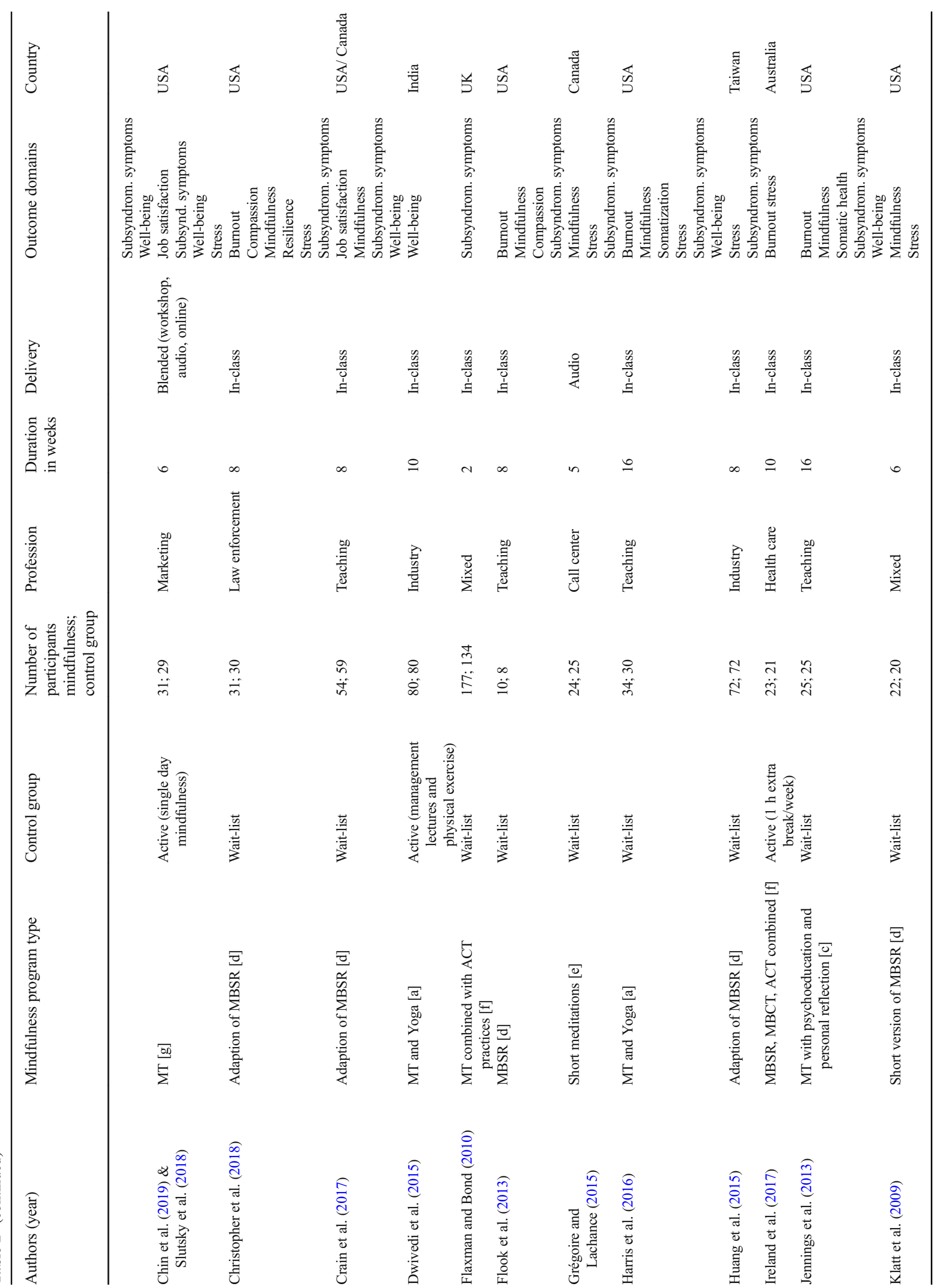




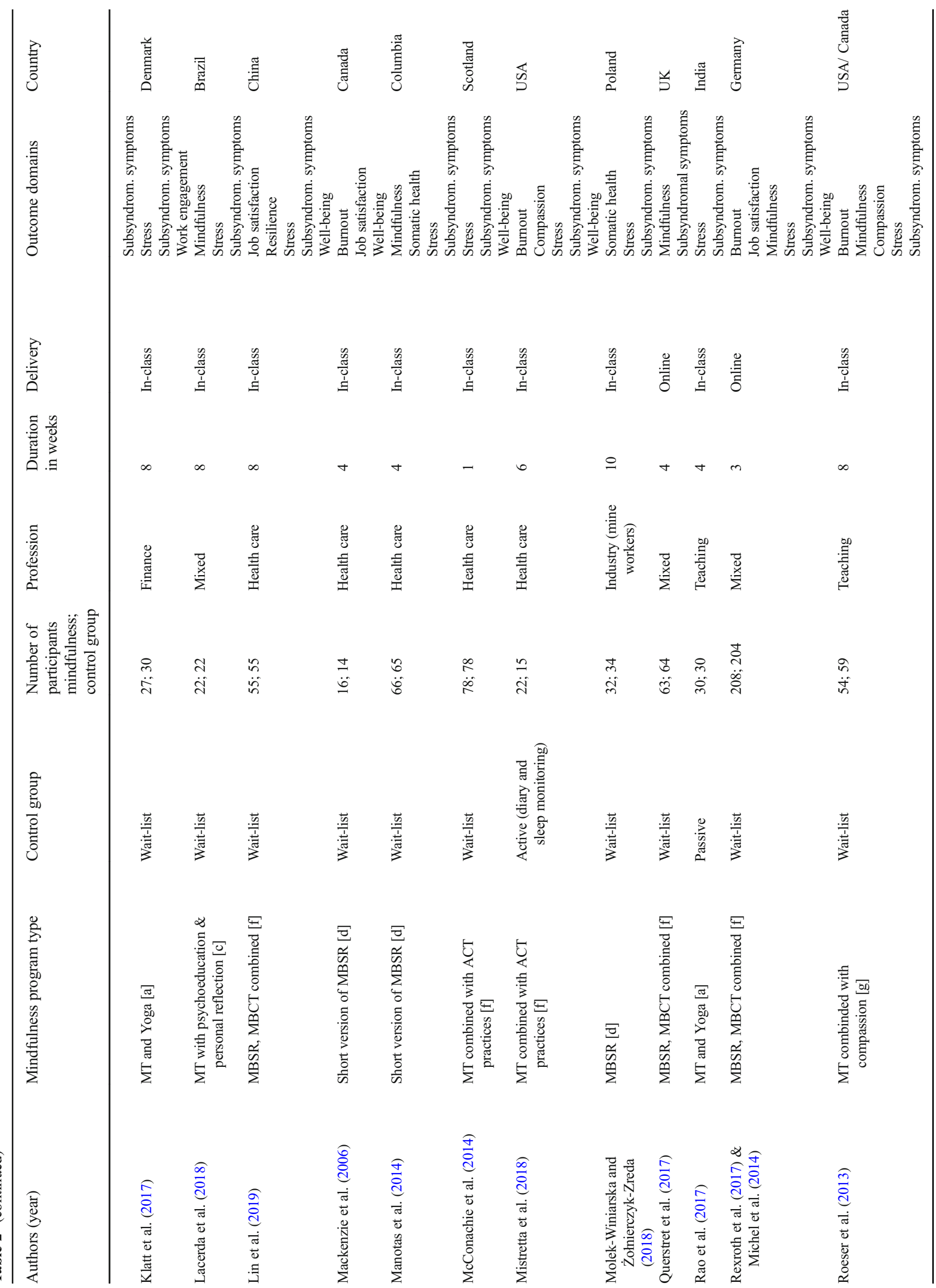




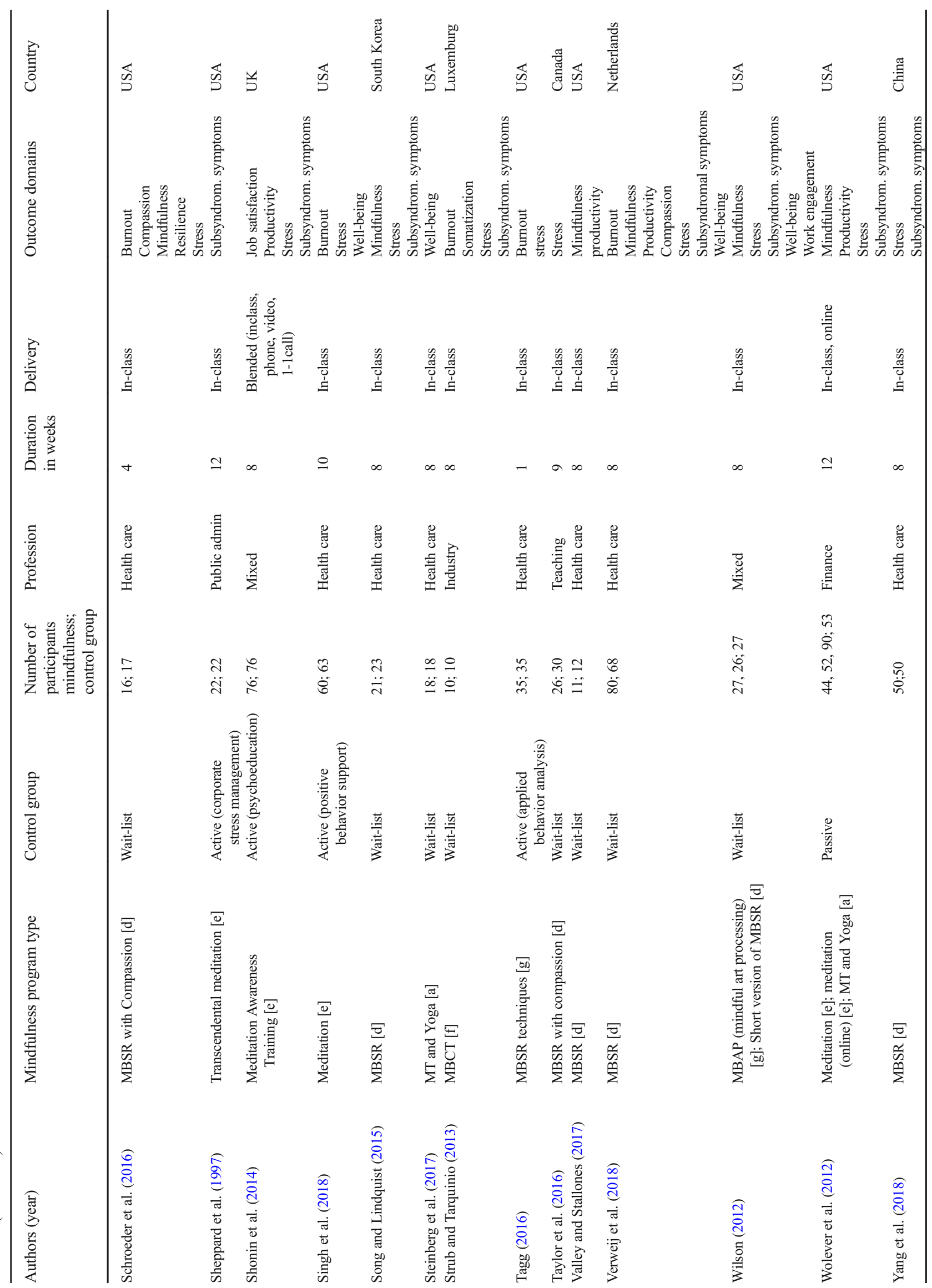


Effects for follow-up assessments up to 12 weeks after the completion of MBPs were only reported in 18 studies (34\%), which in sum did not provide enough data to analyze effects on somatization/physical illness, resilience, and work-related outcomes $(k<4)$. All other outcome categories yielded significant effects in the intended direction, with effect sizes comparable to post-assessment (see Table 3). Largest effects resulted for perceived stress $(g=-0.77, p<.001 ; k=15)$ and subsyndromal symptoms $(g=-0.69, p<.001 ; k=14)$. Sensitivity analyses detected influential cases in the categories perceived stress and subsyndromal symptoms. The exclusion of those outliers lowered the effect sizes by 0.11 and 0.15 , respectively, but did not affect the significance of results (subsyndromal symptoms: stress: $\mathrm{g}=-0.66, \mathrm{p}<.001, \mathrm{k}=13 ; g=-0.54, p<.001, k=14)$.

\section{Exploratory Moderator Analyses}

Exploratory moderator analyses were conducted for the review outcomes mindfulness, well-being/life satisfaction, stress, subsyndromal symptoms, and burnout (see Table 3; Pincus et al. 2011). Overall, the results revealed no consistent moderating effects for any characteristics of populations, programs, and methods. Some variables significantly influenced effects on individual outcomes: Programs involving more hours of attendance yielded larger effects in mindfulness $(Q[1]=5.11, p=.024, k=30)$, burnout $(Q[1]=12.85$, $p<.001, k=21)$, and well-being/life satisfaction $(Q[1]=$ $7.75, p=.005, k=21)$. The sample characteristics gender and occupational profession significantly moderated effects on well-being/life satisfaction (gender: $Q[1]=6.76, p=.009$, $k=22$; profession: $Q[7]=21.39, p=.003, k=22$ ), with larger effect sizes in samples including more male participants, and employees in the financial sector. Participants' level of education significantly moderated effects on well-being/life satisfaction and subsyndromal symptoms, indicating larger effects for higher educated participants (well-being $Q[1]=6.12$, $p=.013, k=5$; subsyndromal symptoms $Q[1]=10.02$, $p=.002, k=14$ ), whereas higher work experience was associated with larger effects in mindfulness $(Q[1]=6.13$, $p=.013, k=12)$ and burnout $(Q[1]=8.67, p=.003, k=10)$. No significant moderator effects were observed for age of participants, type of program, time span in weeks, method and location of delivery, recommended hours of practice at home, type of control group, ITT samples, or publication date (see Appendix $\mathrm{C}$ for detailed results).

\section{Risk of Bias}

Statistical testing for funnel plot asymmetry indicated a potential publication bias for the review outcomes perceived stress $(t[41]=-2.61, p=.013)$ and mindfulness $(t[30]=2.88$, $p<.01)$. Ratings of risk of bias domains are presented in Fig. 2 (see Appendix D for detailed ratings). Most "high-risk" 
Table 3 Comparison of the mindfulness program and control groups at different assessment times

\begin{tabular}{|c|c|c|c|c|c|c|c|c|}
\hline \multirow[b]{2}{*}{ Domain/review Outcome } & \multicolumn{4}{|c|}{ Post $(M=8.42, S D=5.18$ weeks $)$} & \multicolumn{4}{|c|}{ Follow-up ( $\leq 12$ weeks) } \\
\hline & $k$ & $g$ & $C I$ & $I^{2}$ & $k$ & $g$ & $C I$ & $I^{2}$ \\
\hline \multicolumn{9}{|l|}{ Mindfulness } \\
\hline Mindfulness & 32 & $0.44 * * *$ & {$[0.32 ; 0.56]$} & 52.4 & 11 & $0.45^{* * *}$ & {$[0.22 ; 0.68]$} & 62.1 \\
\hline \multicolumn{9}{|l|}{ Mental well-being } \\
\hline Well-being and life satisfaction & 22 & $0.68 * *$ & {$[0.24 ; 1.12]$} & 95.3 & 9 & $0.40 * * *$ & {$[0.22 ; 0.58]$} & 26.1 \\
\hline Compassion & 8 & $0.61 * * *$ & {$[0.37 ; 0.85]$} & 30.7 & 5 & $0.54 * *$ & {$[0.20 ; 0.88]$} & 41.5 \\
\hline \multicolumn{9}{|l|}{ Stress and health impairment } \\
\hline Perceived stress & 43 & $-0.66 * * *$ & {$[-0.88 ;-0.44]$} & 89.8 & 15 & $-0.77 * * *$ & {$[-1.06 ;-0.48]$} & 82.7 \\
\hline Subsyndromal symptoms & 40 & $-0.56^{* * *}$ & {$[-0.79 ;-0.33]$} & 91.5 & 14 & $-0.69 * *$ & {$[-1.03 ;-0.34]$} & 90.7 \\
\hline Burnout & 22 & $-0.37 * *$ & {$[-0.61 ;-0.14]$} & 78.2 & 9 & $-0.38 * * *$ & {$[-0.58 ;-0.19]$} & 25.3 \\
\hline Somatization/physical illness & 6 & $-0.32 *$ & {$[-0.58 ;-0.06]$} & 38.5 & & & & \\
\hline \multicolumn{9}{|l|}{ Work outcomes } \\
\hline Work engagement & 5 & $0.53 *$ & {$[0.08 ; 0.98]$} & 80.3 & & & & \\
\hline Productivity & 9 & $0.35 *$ & {$[0.02 ; 0.68]$} & 79.7 & & & & \\
\hline Job satisfaction & 7 & $0.48 *$ & {$[0.07 ; 0.89]$} & 83.9 & & & & \\
\hline \multicolumn{9}{|l|}{ Resilience } \\
\hline Resilience & 4 & $0.49 * * *$ & {$[0.24 ; 0.73]$} & 0 & & & & \\
\hline
\end{tabular}

$k$ number of trials, $g$ standardized mean difference scores (Hedges' g), $C I$ 95\% confidence intervals, $I^{2}$ heterogeneity statistics, $M$ mean score, $S D$ standard deviation

$* * * p<.001 ; * * p<.01 ; * p<.05$

ratings were assigned in the categories "incomplete outcome data" and "other biases" ( $k=11$ out of 53 each). Risks of bias regarding outcome data either concerned unexplained attrition/ exclusion of participants or a discrepancy between the number of participants and corresponding figures in the statistical analyses (e.g., degrees of freedom). Within the category "other bias," six primary studies reported baseline imbalances, which might have affected outcomes, four included a selective sample of employees with poor mental health and in one some participants changed groups (control to MBP and vice-versa) and were not excluded from the analysis. Three studies were rated as high risk in the category "selective reporting" because they did not report data for at least one of the outcome scales listed in the "Method" section. Five studies were rated as high risk in the category "random sequence generation" because non-random components in the sequence-generation process were described (e.g., volunteering participants in their preferred groups, no full randomization possible because of vacation and schedule issues). The majority of studies did not report in sufficient detail on sequence generation $(k=24)$ and allocation concealment $(k=45)$.

\section{Discussion}

This meta-analysis systematically analyzed the effects of mindfulness-based programs on different outcomes in occupational settings. In total, 56 articles with $n=2689$ program participants and $n=2472$ employees in control groups were included. Our analyses indicate that mindfulness in the workplace effectively reduces perceived stress and health complaints while improving well-being and work-related outcomes (work engagement, productivity, job satisfaction)_-all with small to medium effect sizes ranging from $g=0.32$ to 0.68 shortly after completing the program. Effects were maintained in follow-up assessments up to 3 months later, with effect sizes ranging from $g=0.38$ to 0.77 . Sensitivity analyses confirmed the robustness of findings by still yielding significant effects after excluding primary studies identified as outliers, with one exception (i.e., effects on productivity) and two outcomes not allowing further analyses due to the low number of primary effect sizes (i.e., effects on resilience and work engagement). Heterogeneity of synthesized effect sizes was medium-to-high for the majority of review outcomes, but not explained consistently by population or program characteristics in the moderator analyses.

Our results support the conclusion of previous qualitative and quantitative reviews that mindfulness training in the workplace improves the well-being and health of participants (e.g., Eby et al. 2019; Janssen et al. 2018; Lomas et al. 2017a). Between-group effect sizes were largest for the review outcomes well-being/life satisfaction $(g=0.68)$ and stress $(g=$ -0.66) and comparable in strength to those reported in metaanalyses of MBPs in healthy samples outside the occupational 
Fig. 2 Risk of bias assessment for the included studies. Risk of bias was independently assessed by two reviewers. Conflicts were resolved in discussion with all authors. Blinding of the participants and personnel (performance bias) and blinding of the outcomes assessment (detection bias) were not rated because blinding in randomized controlled behavioral trials is normally not possible
Risk of Bias Assessment for the Included Studies

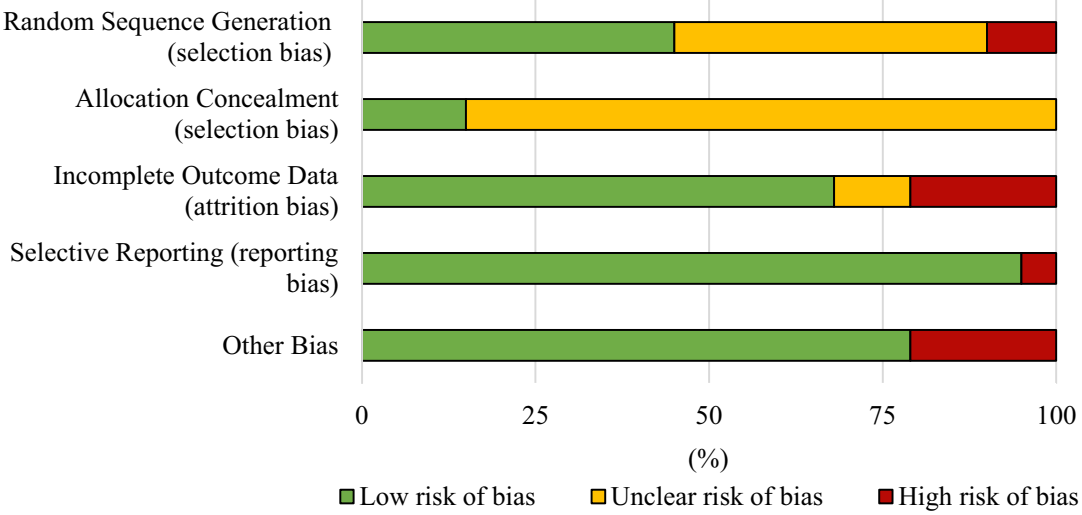

context (Hendriks et al. 2017; Jayawardene et al. 2017; Khoury et al. 2015; Spijkerman et al. 2016). Due to the strong increase in published RCTs in the years 2016 to 2018, this meta-analysis extends two recently published meta-analyses (Bartlett et al. 2019; Lomas et al. 2019) by breadth of information. Our database was large enough to pool effect sizes for follow-up assessments and to perform analyses on review outcomes for which previously not enough primary effect sizes had been reported, namely resilience $(g=0.49)$, job satisfaction $(g=0.48)$, work engagement $(g=0.53)$, productivity $(g=$ $0.35)$, and somatization $(g=0.32)$. In the interpretation of results, some differences have to be considered. Compared to our inclusion criteria, Lomas et al. (2019) applied a broader scope by including student populations $(k=35)$, while Bartlett et al. (2019) focused on "pure" MBPs delivered at the workplace $(k=23)$. Our analyses were based on $56 \mathrm{RCTs}$, of which 20 were included in Lomas et al. (2019) and 15 in Bartlett et al. (2019), yielding a $65 \%$ overlap of primary studies each. Noticeably, the major reason for the discrepancies was a lack of statistical information in the publication of study results, which we requested in vain the authors. Despite these differences, results largely corresponded in synthesized effect sizes for mindfulness $\left(g=0.44 ; g_{\text {Lomas et al. }}=0.39 ; g_{\text {Bartlett et al. }}=\right.$ $0.45)$, perceived stress $\left(g=-0.66 ; g_{\text {Lomas et al. }}=-0.60\right.$; $\left.g_{\text {Bartlett et al. }}=-0.56\right)$, subsyndromal symptoms $(g=-0.48$; $g_{\text {Lomas et al. }}=-0.48$ to $-0.57 ; g_{\text {Bartlett et al. }}=-0.38$ to -0.69$)$, and burnout $\left(g=-0.37, g_{\text {Lomas et al. }}=-0.36 ; g_{\text {Bartlett et al. }}=-\right.$ 0.16 to -0.52$)$. Effect sizes were larger in our analyses for well-being $\left(g=0.68 ; g_{\text {Lomas et al. }}=0.36 ; g_{\text {Bartlett et al. }}=0.46\right)$ and compassion $\left(g=0.61 ; g_{\text {Lomas et al. }}=0.42\right)$.

Empirical evidence on the proposed improvements in workplace functioning, performance, and productivity is still limited, although these outcomes are frequently discussed in scientific literature (e.g., Hyland et al. 2015) and most likely present decisive arguments for implementing MBPs in forprofit organizations (e.g., Greiser and Martini 2018). Workrelated outcomes were only assessed in a small number of primary studies $(k=16)$, and caution must be applied in the extrapolation of results. In the main analyses, MBPs yielded significant positive effects on all three review outcomes - job satisfaction, work engagement, and productivity. However, only the increase in job satisfaction $(g=0.48)$ demonstrated to be robust in the sensitivity analyses. The effect on productivity $(g=0.35)$ was attributable to a single study on meditation awareness training in white-collar middle management (Shonin et al. 2014) and dropped below the level of significance among the remaining eight studies. The sensitivity analysis of work engagement $(g=0.53)$ identified two outlying studies, in which one observed no effects following a mindfulness-related multicomponent health promotion intervention (van Berkel et al. 2014) and one observed a comparatively larger effect after a mindfulness-based art processing intervention (Wilson 2012). Due to the small number of studies reporting on work engagement $(k=5)$, an amended analysis was not feasible for this outcome.

Effects on job satisfaction, work engagement, and productivity have not previously been synthesized metaanalytically as separate review outcomes. The preliminary nature of results is particularly pronounced in effects on productivity, due to the heterogeneous measures used to assess this outcome in the six primary studies reporting on this category. Two studies (partly) assessed productivity based on external indicators, yielding inconsistent results: Allexandre et al. (2016) report inconclusive patterns in company metrics for employee performance. Bartlett et al. (2017) investigated "health-related lost productive time" based on self-reported "absent days" and "inefficient days," but only the latter significantly decreased. One study applied an observer-based instrument and found significant effects on work performance, as rated by participants' direct line managers (Shonin et al. 2014). Three studies assessed effects on self-report questionnaires - along with all other primary outcomes included in this meta-analysis. Participating in a MBP did not improve the ability to perform job roles in one study (Wolever et al. 2012), yielded marginally significant reductions in medical error rate (Verweij et al. 2018), but 
significantly decreased cognitive failures (Valley and Stallones 2017).

\section{Moderator Analyses}

In the moderator analyses, none of the population, program or methodological characteristics explained heterogeneity systematically across review outcomes, which aligns with the findings of other reviews (e.g., Janssen et al. 2018). Regarding the program characteristics, neither the type of program nor aspects of delivery (in class vs. online, location) significantly influenced effects on any outcome. However, our analyses might have been underpowered to detect moderating effects. First, we did not confine our analysis to one specific mindfulness training method to account for the naturally occurring high variability of workplace-specific adaptations. Second, aspects of delivery are unequally distributed with $79 \%$ programs delivered in-class and $68 \%$ delivered on-site. Previous meta-analyses across contexts yield inconsistent results. Lomas et al. (2019) report larger effects on health-related outcomes for standardized MBSR versions, whereas Bartlett et al. (2019) and Bamber and Morpeth (2019) did not find any moderating effects for MBP type and content. A growing body of research suggests that particular training components, meditation techniques, and mindfulness practices contribute differentially to effects on some outcomes (e.g., Hunt et al. 2018; Kropp and Sedlmeier 2019). Two recent meta-analyses indicate that programs with elements of various informal and formal meditation practices yield larger effects on negative affectivity (Schumer et al. 2018) and weight loss (Carrière et al. 2018). Considering the high relevance of time-savings, accessibility, and costefficiency in occupational contexts, research on these differential effects might be of interest in workplace health promotion.

The analyses of treatment dosage concur with a previously reported pattern: In line with earlier reviews (Carmody and Baer 2009; Virgili 2015), the duration of programs in weeks was not directly related to their effectiveness. Hours of attendance on the other hand was significantly associated with higher improvements in mindfulness, well-being/life satisfaction and reduction of burnout symptoms, supporting the theoretical assumption that mindfulness requires a certain amount of practice (e.g., Bishop et al. 2004; Tang et al. 2015). Laboratory studies have suggested positive short-term effects of mindfulness inductions (Leyland et al. 2018). However, how much minimum training is required to yield sustainable effects remains uncertain. In a meta-analysis of 43 studies on MBSR and MBCT, the dose-response relationship was statistically significant, but unexpectedly small (Parsons et al. 2017); in an analysis of 15 RCT's evaluating online programs, it seemed to be driven by an outlier (Spijkerman et al. 2016). Possibly, the dose-response relationship can only be understood in a more comprehensive model, including variables such as motivation, practice quality, or self-efficacy (e.g., Goldberg et al. 2019).

Moderator analyses for population characteristics include several possible biases that impede a conclusive interpretation of results. Effects on well-being/life satisfaction were significantly moderated by gender, education, and occupational profession; effects on subsyndromal symptoms by education; and effects on mindfulness and burnout by work experience. However, the effects of gender and profession on well-being/life satisfaction might be biased by the strong effect sizes of one singular study with a rather unusual sample of midlevel managers (50\% male), which were recruited across 30 companies in the financial sector (Żołnierczyk-Zreda et al. 2016). In addition, results might be skewed by the unbalanced distribution of participant characteristics among primary samples, including an overrepresentation of women and participants with college degrees. Although these characteristics concur with the selective utilization of preventive health care (Dryden et al. 2012; Koopmans et al. 2012), they might rather be caused by the large number of samples working in health care $(36 \%)$ and education $(17 \%)$. The insignificant results regarding age might be methodologically biased. We applied a meta-analytical approach using summary statistics at the study level. Consequently, the moderator analysis on age tested whether the average age of participants within samples was associated with differences in effects between samples. Considering the multiple sources of heterogeneity across and within different occupational settings, the investigation of moderators among participant characteristics would require large multi-site trials including participants with different professional backgrounds and current occupations.

Among the formal characteristics of primary studies, neither the year of publication nor the analyzed methodological characteristics significantly moderated any of the review outcomes. In psychotherapy research, the potential moderating effect of publication date has been controversially discussed based on studies published 1977 to 2014 (Johnsen and Friborg 2015; Ljótsson et al. 2017). Considering that the earliest study included in our review had been published in 1997, the proposed influence of early research might not apply to research on MBPs in the occupational setting. The insignificant results for type of control group and methods for the handling of missing data align with previous reviews (e.g., DonaldsonFeilder et al. 2019; Khoury et al. 2017; Schumer et al. 2018) but deserve further attention. In our analyses, only 11 primary studies $(21 \%)$ compared the MBPs to active control groups and less than half $(k=21,40 \%)$ applied statistical methods to control for systematic biases in missing data. Both methods are common indicators for the methodological quality of intervention studies (e.g., Ruiz-Canela et al. 2000), because they yield a more realistic estimation of effectiveness, which is reflected in lower between-group effect sizes. Research on 
MBSR indicates rigorous active control groups can indeed yield comparable effects on outcomes other than mindfulness itself (e.g., MacCoon et al. 2012). Thus, more research is needed to identify possible unique effects of mindfulness training compared to other effective workplace health promotion programs (c.f. Goetzel et al. 2014).

\section{Limitations and Future Research}

Although we conducted this review according to state-of-theart meta-analytic methods, our results are subject to several inherent limitations. We applied a broad search strategy and contacted authors to minimize publication bias among the included primary studies. For most review outcomes, no graphical or statistical funnel plot asymmetry was detected. However, potential publication bias was observed for the effects on mindfulness and perceived stress. Results regarding these two review outcomes should therefore be interpreted with special caution, as the observed effect size might be overestimated.

The quality of primary studies was evaluated with the Cochrane Collaboration tool for assessing the risk of bias (Higgins et al. 2011). The majority of studies did not imply a high risk of bias in any of the categories, indicating an acceptable overall quality of primary studies. Most highrisk ratings were assigned in the category "incomplete outcome data" and "other biases" $(k=11,21 \%$ of primary studies each), "random sequence generation" $(k=5)$ and "selective reporting" $(k=3)$. Risks of bias regarding outcome data either concerned unexplained attrition/exclusion of participants or discrepancies in the number of participants across text, tables, and statistical analyses. The category other biases included baseline imbalances between control and intervention group in variables related to outcome measures $(k=6)$, selective samples of employees with poor mental health $(k=4)$, and participants switching bi-directionally between control and intervention groups $(k=1)$. Risk of bias in random sequence generation was assigned mainly for manual modifications in the randomization process, such as adjusting for preferences, vacations, or schedule issues. The category "selective reporting" applied if no data were reported for at least one of the outcome scales mentioned in the methods section of an article. However, most studies did not or not in sufficient detail report on the sequence generation and the allocation concealment, resulting in a large proportion of ratings of "unclear risk of bias" in these categories. It would be beneficial to report on these aspects more precisely in future studies to facilitate the conductance andmore importantly - the interpretation of meta-analyses on health interventions.

Finally, data from primary studies was not sufficient to estimate effect sizes for long-term effects. Only seven of 53 included studies report a follow-up period of more than 12 weeks, whereby in two of these studies, the waiting list group had received the training by the time of assessment. A closer look at the results reveals a mixed picture. In some studies, the beneficial effects of mindfulness training were maintained or further improved over a period of 6 months $(k=3)$ or 1 and 3 years, respectively (each $k=1$ ). One study reports only marginal between-group effects at 4 months after the program $(k=1)$; another study did not find any effects within 1 year $(k=1)$. The shortage of longer follow-up periods is not specific to the occupational context but applies to the evaluation of mindfulness programs across research areas, such as general mental health prevention (Khoury et al. 2015), clinical psychology (Galante et al. 2013; Singh and Gorey 2018; Strauss et al. 2014), physical health (Haller et al. 2017), and primary care (Demarzo et al. 2015).

\section{Implications for Practice}

For organizations and corporations that consider implementing mindfulness training into their occupational health management, our results provide evidence for its effectiveness in promoting personal health and well-being. Based on the available evidence, these generally positive effects seem to be applicable across professions and individual characteristics of participants, indicating that mindfulness training is feasible and scalable in a wide range of contexts.

However, our results do not offer conclusive answers to a variety of questions and concerns that have been raised (e.g., Hyland et al. 2015; Jamieson and Tuckey 2017). First, we only included studies evaluating mindfulness-based programs targeting individual employees. Current research suggests that organizational culture, the mindfulness of leaders, and other setting variables not only influence the collective mindfulness within corporations (Sutcliffe et al. 2016) but are also beneficially associated with individual outcomes (e.g., Pinck and Sonnentag 2017; Reb et al. 2015). These variables might also affect the perception and acceptance of individually oriented mindfulness training within occupational health strategies. In the worst case, if mindfulness training is offered as a "means to pacify disgruntled employees, maintain the status quo, and ultimately manage and manipulate the workforce" (Hyland et al. 2015, p.595), they might not be as effective as the results of these analyses suggest. Future studies should consider these environmental factors, which might facilitate or hinder mindfulness at different hierarchical levels within organizations.

Second, mindfulness has often been promoted as an approach to improve individual and organizational performance (e.g., Hyland et al. 2015). Some researchers base this assumption on promising results from cross-sectional research (see Mesmer-Magnus et al. 2017), others refer to hypothetical mechanisms of mindfulness (Good et al. 2016), and some build on the happy worker-productive worker thesis, 
suggesting that workers who experience high levels of wellbeing also perform well and vice-versa. Although a variety of performance and productivity outcomes have been studied in quasi-experimental and uncontrolled studies with inconsistent results (Lomas et al. 2017b), productivity measures have only rarely been included in RCTs and yielded no robust significant results in our analysis. Future studies should include measures targeting individual job and task performance directly, as well as measures contributing to a corporation's overall productivity (e.g., presenteeism, absenteeism) to provide more robust data on whether mindfulness trainings are effective in increasing performance.

In summary, our meta-analysis shows solid evidence $(k \geq 22)$ that MBPs in the workplace have positive effects on perceived stress, subsyndromal symptoms, burnout, mindfulness and well-being, across different occupational groups and organizational structures. These effects seem to persist over a period of 3 months. In addition, our results show preliminary evidence of an increase in compassion, job satisfaction, work engagement, and resilience and a reduction in somatic complaints $(k \leq 8)$. Future studies should further investigate the potential effects of MBPs on work-related outcomes, in particular on performance and productivity measures $(k=9)$ and include active control groups in their study design.

Author Contributions RV collaborated with the design and executed the study, conducted the data analyses, and wrote the first draft of the paper. MBi collaborated with the design and execution of the study. MBo supervised the study and collaborated in the writing and editing of the final manuscript. LL designed the study, supervised the execution and data analyses, and assisted the writing of the paper. All authors approved the final version of the manuscript for submission.

Additional Contributions We thank Mareike Fischer and Monika Hessemer for assisting in the preparation of this manuscript, as well as Sirid Schubert, Lyn Lücke, Sophie Heidemann, Eva Buetow, and Marie Hamm for data entry support.

Funding Information Open Access funding provided by Projekt DEAL.

\section{Compliance with Ethical Standards}

This research received no specific grant from any funding agency, commercial or not-for-profit sectors. This article does not contain any studies with human participants or animals performed by any of the author. This research is collecting and synthesizing data from previous trials, in which informed consent has already been obtained by the trial investigators.

Conflict of Interest The authors declare that they have no conflict of interest.

Open Access This article is licensed under a Creative Commons Attribution 4.0 International License, which permits use, sharing, adaptation, distribution and reproduction in any medium or format, as long as you give appropriate credit to the original author(s) and the source, provide a link to the Creative Commons licence, and indicate if changes were made. The images or other third party material in this article are included in the article's Creative Commons licence, unless indicated otherwise in a credit line to the material. If material is not included in the article's Creative Commons licence and your intended use is not permitted by statutory regulation or exceeds the permitted use, you will need to obtain permission directly from the copyright holder. To view a copy of this licence, visit http://creativecommons.org/licenses/by/4.0/.

\section{References}

All studies included in this meta-analysis are indicated by $(*)$

*Aikens, K. A., Astin, J., Pelletier, K. R., Levanovich, K., Baase, C. M., Park, Y. Y., et al. (2014). Mindfulness goes to work: impact of an online workplace intervention. Journal of Occupational and Environmental Medicine, 56(7), 721-731.

*Alexander, G. K., Rollins, K., Walker, D., Wong, L., \& Pennings, J. (2015). Yoga for self-care and burnout prevention among nurses. Workplace Health \& Safety, 63(10), 462-470.

*Allexandre, D., Bernstein, A. M., Walker, E., Hunter, J., Roizen, M. F., $\&$ Morledge, T. J. (2016). A web-based mindfulness stress management program in a corporate call center: a randomized clinical trial to evaluate the added benefit of onsite group support. Journal of Occupational and Environmental Medicine, 58(3), 254-264.

*Amutio, A., Martínez-Taboada, C., Delgado, L. C., Hermosilla, D., \& Mozaz, M. J. (2015a). Acceptability and effectiveness of a longterm educational intervention to reduce physicians' stress-related conditions. Journal of Continuing Education in the Health Professions, 35(4), 255-260.

*Amutio, A., Martínez-Taboada, C., Hermosilla, D., \& Delgado, L. C. (2015b). Enhancing relaxation states and positive emotions in physicians through a mindfulness training program: a one-year study. Psychology, Health \& Medicine, 20(6), 720-731.

*Ancona, M. R., \& Mendelson, T. (2014). Feasibility and preliminary outcomes of a yoga and mindfulness intervention for school teachers. Advances in School Mental Health Promotion, 7(3), 156-170.

*Anderson, V. L., Levinson, E. M., Barker, W., \& Kiewra, K. R. (1999). The effects of meditation on teacher perceived occupational stress, state and trait anxiety, and burnout. School Psychology Quarterly, 14(1), 3-25.

*Arredondo, M., Sabaté, M., Valveny, N., Langa, M., Dosantos, R., Moreno, J., et al. (2017). A mindfulness training program based on brief practices (M-PBI) to reduce stress in the workplace: a randomised controlled pilot study. International Journal of Occupational and Environmental Health, 23(1), 40-51.

*Asuero, A. M., Queraltó, J. M., Pujol-Ribera, E., Berenguera, A., Rodriguez-Blanco, T., \& Epstein, R. M. (2014). Effectiveness of a mindfulness education program in primary health care professionals: a pragmatic controlled trial. Journal of Continuing Education in the Health Professions, 34(1), 4-12.

*Auserón, G. A., Viscarret, M. R. E., Goñi, C. F., Rubio, V. G., Pascual, P. P., \& de Sainz Murieta, García de Galdeano, E. (2018). Evaluación de la efectividad de un programa de mindfulness y autocompasión para reducir el estrés y prevenir el burnout en profesionales sanitarios de atención primaria. Atención Primaria, 50(3), 141-150.

Baas, M., Nevicka, B., \& Ten Velden, F. S. (2014). Specific mindfulness skills differentially predict creative performance. Personality and Social Psychology Bulletin, 40(9), 1092-1106.

*Baby, M., Gale, C., \& Swain, N. (2019). A communication skills intervention to minimise patient perpetrated aggression for healthcare 
support workers in New Zealand: a cluster randomised controlled trial. Health \& Social Care in the Community, 27(1), 170-181.

Bamber, M. D., \& Morpeth, E. (2019). Effects of mindfulness meditation on college student anxiety: a meta-analysis. Mindfulness, 10(2), 203-214.

Barns, R. (2017). Distress, wellbeing and mindfulness amongst mental health professionals. Doctoral Dissertation, University of Sheffield, Sheffield.

*Bartlett, L., Lovell, P., Otahal, P., \& Sanderson, K. (2017). Acceptability, feasibility, and efficacy of a workplace mindfulness program for public sector employees: a pilot randomized controlled trial with informant reports. Mindfulness, 8(3), 639-654.

Bartlett, L., Martin, A., Neil, A. L., Memish, K., Otahal, P., Kilpatrick, M., et al. (2019). A systematic review and meta-analysis of workplace mindfulness training randomized controlled trials. Journal of Occupational Health Psychology, 24(1), 108-126.

Bishop, S. R., Lau, M., Shapiro, S., Carlson, L., Anderson, D. R., Carmody, J., et al. (2004). Mindfulness: a proposed operational definition. Clinical Psychology: Science and Practice, 11(3), 230-241.

Boellinghaus, I., Jones, F. W., \& Hutton, J. (2014). The role of mindfulness and loving-kindness meditation in cultivating self-compassion and other-focused concern in health care professionals. Mindfulness, 5(2), 129-138.

*Bostock, S., Crosswell, A., Prather, A., \& Steptoe, A. (2018). Mindfulness on-the-go: effects of a mindfulness meditation app on work stress and well-being. Journal of Occupational Health Psychology, 24(1), 127-138.

Burton, A., Burgess, C., Dean, S., Koutsopoulou, G. Z., \& Hugh-Jones, S. (2017). How effective are mindfulness-based interventions for reducing stress among healthcare professionals? A systematic review and meta-analysis. Stress and Health, 33(1), 3-13.

Carmody, J., \& Baer, R. A. (2009). How long does a mindfulness-based stress reduction program need to be? A review of class contact hours and effect sizes for psychological distress. Journal of Clinical Psychology, 65(6), 627-638.

Carrière, K., Khoury, B., Günak, M. M., \& Knäuper, B. (2018). Mindfulness-based interventions for weight loss: a systematic review and meta-analysis. Obesity Reviews, 19(2), 164-177.

*Cheema, B. S., Houridis, A., Busch, L., Raschke-Cheema, V., Melville, G. W., Marshall, P. W., et al. (2013). Effect of an office worksitebased yoga program on heart rate variability: outcomes of a controlled trial. BMC Complementary and Alternative Medicine, 13(1), e82.

*Chin, B., Slutsky, J., Raye, J., \& Creswell, J. D. (2019). Mindfulness training reduces stress at work: a randomized controlled trial. Mindfulness, 10(4), 627-638.

*Christopher, M. S., Hunsinger, M., Goerling, L. R. J., Bowen, S., Rogers, B. S., Gross, C. R., et al. (2018). Mindfulness-based resilience training to reduce health risk, stress reactivity, and aggression among law enforcement officers: a feasibility and preliminary efficacy trial. Psychiatry Research, 264, 104-115.

Cochran, W. G. (1954). The combination of estimates from different experiments. Biometrics, 10, 101-129.

Cohen, J. (1988). Statistical power analysis for the behavioral sciences (2nd Edition ed.). Hillsdale: Lawrence Erlbaum.

*Crain, T. L., Schonert-Reichl, K. A., \& Roeser, R. W. (2017). Cultivating teacher mindfulness: effects of a randomized controlled trial on work, home, and sleep outcomes. Journal of Occupational Health Psychology, 22(2), 138-152.

Demarzo, M. M. P., Montero-Marin, J., Cuijpers, P., Zabaleta-del-Olmo, E., Mahtani, K. R., Vellinga, A., et al. (2015). The efficacy of mindfulness-based interventions in primary care: a meta-analytic review. The Annals of Family Medicine, 13(6), 573-582.

Donaldson-Feilder, E., Lewis, R., \& Yarker, J. (2019). What outcomes have mindfulness and meditation interventions for managers and leaders achieved? A systematic review. European Journal of Work and Organizational Psychology, 28(1), 11-29.
Dryden, R., Williams, B., McCowan, C., \& Themessl-Huber, M. (2012). What do we know about who does and does not attend general health checks? Findings from a narrative scoping review. BMC Public Health, 12(1), e723.

*Dwivedi, U., Kumari, S., Akhilesh, K. B., \& Nagendra, H. R. (2015). Well-being at workplace through mindfulness: influence of yoga practice on positive affect and aggression. Ayu, 36(4), 375-379.

Eby, L. T., Allen, T. D., Conley, K. M., Williamson, R. L., Henderson, T. G., \& Mancini, V. S. (2019). Mindfulness-based training interventions for employees: a qualitative review of the literature. Human Resource Management Review, 29(2), 156-178.

Egger, M., Smith, G. D., Schneider, M., \& Minder, C. (1997). Bias in meta-analysis detected by a simple, graphical test. British Medical Journal, 315, 629-634.

Escuriex, B. F., \& Labbé, E. E. (2011). Health care providers' mindfulness and treatment outcomes: a critical review of the research literature. Mindfulness, 2(4), 242-253.

*Flaxman, P. E., \& Bond, F. W. (2010). Acceptance and commitment training: promoting psychological flexibility in the workplace. In R. H. Baer (Ed.), Assessing mindfulness and acceptance processes in clients: illuminating the theory and practice of change (pp. 282306). Oakland: New Harbinger Publications.

*Flook, L., Goldberg, S. B., Pinger, L., Bonus, K., \& Davidson, R. J. (2013). Mindfulness for teachers: a pilot study to assess effects on stress, burnout, and teaching efficacy. Mind, Brain, and Education, 7(3), 182-195.

Galante, J., Iribarren, S. J., \& Pearce, P. F. (2013). Effects of mindfulnessbased cognitive therapy on mental disorders: a systematic review and meta-analysis of randomised controlled trials. Journal of Research in Nursing, 18(2), 133-155.

Gelles, D. (2015). Mindful work: Hhow meditation is changing business from the inside out. New York: Houghton Mifflin Harcourt.

Glomb, T. M., Duffy, M. K., Bono, J. E., \& Yang, T. (2011). Mindfulness at work. In J. Martocchio, H. Liao, \& A. Joshi (Eds.), Research in personnel and human resource management (pp. 115-157). Bingley: Emerald Group Publishing Limited.

Goetzel, R. Z., Henke, R. M., Tabrizi, M., Pelletier, K. R., Loeppke, R., Ballard, D. W., et al. (2014). Do workplace health promotion (wellness) programs work? Journal of Occupational and Environmental Medicine, 56(9), 927-934.

Goldberg, S. B., Knoeppel, C., Davidson, R. J., \& Flook, L. (2019). Does practice quality mediate the relationship between practice time and outcome in mindfulness-based stress reduction? Journal of Counseling Psychology, 67(1), 115-121.

Good, D. J., Lyddy, C. J., Glomb, T. M., Bono, J. E., Brown, K. W., Duffy, M. K., et al. (2016). Contemplating mindfulness at work: an integrative review. Journal of Management, 42(1), 114-142.

*Grégoire, S., \& Lachance, L. (2015). Evaluation of a brief mindfulnessbased intervention to reduce psychological distress in the workplace. Mindfulness, 6(4), 836-847.

Greiser, C., \& Martini, J. P. (2018). Unleashing the power of mindfulness in corporations. Boston consulting group. http://image-src.bcg.com/ Images/BCG-Unleashing-the-Power-of-Mindfulness-inCorporations-Apr-2018 tcm9-190679.pdf. Accessed 15 Dec 2019.

Haller, H., Winkler, M. M., Klose, P., Dobos, G., Kümmel, S., \& Cramer, H. (2017). Mindfulness-based interventions for women with breast cancer: an updated systematic review and meta-analysis. Acta Oncologica, 56(12), 1665-1676.

*Harris, A. R., Jennings, P. A., Katz, D. A., Abenavoli, R. M., \& Greenberg, M. T. (2016). Promoting stress management and wellbeing in educators: feasibility and efficacy of a school-based yoga and mindfulness intervention. Mindfulness, 7(1), 143-154.

Hedges, L., \& Olkin, I. (1985). Statistical methods for meta analysis. Orlando: Academic Press.

Hendriks, T., de Jong, J., \& Cramer, H. (2017). The effects of yoga on positive mental health among healthy adults: a systematic review 
and meta-analysis. The Journal of Alternative and Complementary Medicine, 23(7), 505-517.

Higgins, J. P. T., Altman, D. G., Gøtzsche, P. C., Jüni, P., Moher, D., Oxman, A. D., et al. (2011). The Cochrane Collaboration's tool for assessing risk of bias in randomised trials. British Medical Journal, 343, e5928.

Higgins, J. P. T., \& Green, S. (2008). Cochrane handbook for systematic reviews of interventions. Chichester: John Wiley \& Sons Ltd..

Higgins, J. P. T., \& Thompson, S. G. (2002). Quantifying heterogeneity in a meta-analysis. Statistics in Medicine, 21(11), 1539-1558.

Higgins, J. P. T., Thompson, S. G., Deeks, J. J., \& Altman, D. G. (2003). Measuring inconsistency in meta-analyses. British Medical Journal, 327, 557-560.

*Huang, S. L., Li, R. H., Huang, F. Y., \& Tang, F.-C. (2015). The potential for mindfulness-based intervention in workplace mental health promotion: results of a randomized controlled trial. PLoS One, 10(9), e0138089.

Hülsheger, U. R., Alberts, H. J. E. M., Feinholdt, A., \& Lang, J. W. B. (2013). Benefits of mindfulness at work: the role of mindfulness in emotion regulation, emotional exhaustion, and job satisfaction. Journal of Applied Psychology, 98(2), 310-325.

Hunt, M., Al-Braiki, F., Dailey, S., Russell, R., \& Simon, K. (2018). Mindfulness training, yoga, or both? Dismantling the active components of a mindfulness-based stress reduction intervention. Mindfulness, 9(2), 512-520.

Hwang, Y. S., Bartlett, B., Greben, M., \& Hand, K. (2017). A systematic review of mindfulness interventions for in-service teachers: a tool to enhance teacher wellbeing and performance. Teaching and Teacher Education, 64, 26-42.

Hyland, P. K., Lee, R. A., \& Mills, M. J. (2015). Mindfulness at work: a new approach to improving individual and organizational performance. Industrial and Organizational Psychology, 8(4), 576-602.

Iancu, A. E., Rusu, A., Măroiu, C., Păcurar, R., \& Maricuțoiu, L. P. (2017). The effectiveness of interventions aimed at reducing teacher burnout: a meta-analysis. Educational Psychology Review, 30(2), 373-396.

*Ireland, M. J., Clough, B., Gill, K., Langan, F., O'Connor, A., \& Spencer, L. (2017). A randomized controlled trial of mindfulness to reduce stress and burnout among intern medical practitioners. Medical Teacher, 39(4), 409-414.

Irving, J. A., Dobkin, P. L., \& Park, J. (2009). Cultivating mindfulness in health care professionals: a review of empirical studies of mindfulness-based stress reduction (MBSR). Complementary Therapies in Clinical Practice, 15(2), 61-66.

Jacobs, S. J., \& Blustein, D. L. (2008). Mindfulness as a coping mechanism for employment uncertainty. The Career Development Quarterly, 57(2), 174-180.

Jamieson, S. D., \& Tuckey, M. R. (2017). Mindfulness interventions in the workplace: a critique of the current state of the literature. Journal of Occupational Health Psychology, 22(2), 180-193.

Janssen, M., Heerkens, Y., Kuijer, W., van der Heijden, B., \& Engels, J. (2018). Effects of mindfulness-based stress reduction on employees' mental health: a systematic review. PLoS One, 13(1), e0191332.

Jayawardene, W. P., Lohrmann, D. K., Erbe, R. G., \& Torabi, M. R. (2017). Effects of preventive online mindfulness interventions on stress and mindfulness: a meta-analysis of randomized controlled trials. Preventive Medicine Reports, 5, 150-159.

*Jennings, P. A., Frank, J. L., Snowberg, K. E., Coccia, M. A., \& Greenberg, M. T. (2013). Improving classroom learning environments by cultivating awareness and resilience in education (CARE): results of a randomized controlled trial. School Psychology Quarterly, 28(4), 374-390.

Johnsen, T. J., \& Friborg, O. (2015). The effects of cognitive behavioral therapy as an anti-depressive treatment is falling: a meta-analysis. Psychological Bulletin, 141(4), 747-768.

Kabat-Zinn, J. (1990). Full catastrophe living: Using the wisdom of your body and mind to face stress, pain, and illness. New York: Dell Publishing.
Khoury, B., Sharma, M., Rush, S. E., \& Fournier, C. (2015). Mindfulness-based stress reduction for healthy individuals: a metaanalysis. Journal of Psychosomatic Research, 78(6), 519-528.

Khoury, B., Knäuper, B., Schlosser, M., Carrière, K., \& Chiesa, A. (2017). Effectiveness of traditional meditation retreats: a systematic review and meta-analysis. Journal of Psychosomatic Research, 92, 16-25.

*Klatt, M., Norre, C., Reader, B., Yodice, L., \& White, S. (2017). Mindfulness in motion: a mindfulness-based intervention to reduce stress and enhance quality of sleep in Scandinavian employees. Mindfulness, 8(2), 481-488.

*Klatt, M. D., Buckworth, J., \& Malarkey, W. B. (2009). Effects of lowdose mindfulness-based stress reduction (MBSR-ld) on working adults. Health Education \& Behavior, 36(3), 601-614.

Klingbeil, D. A., \& Renshaw, T. L. (2018). Mindfulness-based interventions for teachers: a meta-analysis of the emerging evidence base. School Psychology Quarterly, 33(4), 501-511.

Koopmans, B., Nielen, M. M. J., Schellevis, F. G., \& Korevaar, J. C. (2012). Non-participation in population-based disease prevention programs in general practice. BMC Public Health, 12(1), e856.

Krick, A., \& Felfe, J. (2019). Who benefits from mindfulness? The moderating role of personality and social norms for the effectiveness on psychological and physiological outcomes among police officers. Journal of Occupational Health Psychology. https://doi.org/10. 1037/ocp0000159.

Kropp, A., \& Sedlmeier, P. (2019). What makes mindfulness-based interventions effective? An examination of common components. Mindfulness, 10, 2060-2072.

*Lacerda, S. S., Little, S. W., \& Kozasa, E. H. (2018). A stress reduction program adapted for the work environment: a randomized controlled trial with a follow-up. Frontiers in Psychology, 9, e668.

Lebuda, I., Zabelina, D. L., \& Karwowski, M. (2016). Mind full of ideas: a meta-analysis of the mindfulness-creativity link. Personality and Individual Differences, 93, 22-26.

Leyland, A., Rowse, G., \& Emerson, L. M. (2018). Experimental effects of mindfulness inductions on self-regulation: Systematic review and meta-analysis. Emotion, 19(1), 108-122.

*Lin, L., He, G., Yan, J., Gu, C., \& Xie, J. (2019). The effects of a modified mindfulness-based stress reduction program for nurses: a randomized controlled trial. Workplace Health \& Safety, 67(3), 111-122.

Ljótsson, B., Hedman, E., Mattsson, S., \& Andersson, E. (2017). The effects of cognitive-behavioral therapy for depression are not falling: a re-analysis of Johnsen and Friborg (2015). Psychological Bulletin, 143(3), 321-325.

Lomas, T., Medina, J. C., Ivtzan, I., Rupprecht, S., Hart, R., \& EiroaOrosa, F. J. (2017a). The impact of mindfulness on well-being and performance in the workplace: an inclusive systematic review of the empirical literature. European Journal of Work and Organizational Psychology, 26(4), 492-513.

Lomas, T., Medina, J. C., Ivtzan, I., Rupprecht, S., \& Eiroa-Orosa, F. J. (2017b). The impact of mindfulness on the wellbeing and performance of educators: a systematic review of the empirical literature. Teaching and Teacher Education, 61, 132-141.

Lomas, T., Medina, J. C., Ivtzan, I., Rupprecht, S., \& Eiroa-Orosa, F. J. (2018). A systematic review and meta-analysis of the impact of mindfulness-based interventions on the well-being of healthcare professionals. Mindfulness, 10(7), 1193-1216.

Lomas, T., Medina, J. C., Ivtzan, I., Rupprecht, S., \& Eiroa-Orosa, F. J. (2019). Mindfulness-based interventions in the workplace: an inclusive systematic review and meta-analysis of their impact upon wellbeing. The Journal of Positive Psychology, 14(5), 625-640.

Luken, M., \& Sammons, A. (2016). Systematic review of mindfulness practice for reducing job burnout. American Journal of Occupational Therapy, 70(2), 1-5.

MacCoon, D. G., Imel, Z. E., Rosenkranz, M. A., Sheftel, J. G., Weng, H. Y., Sullivan, J. C., et al. (2012). The validation of an active control 
intervention for mindfulness based stress reduction (MBSR). Behaviour Research and Therapy, 50(1), 3-12.

Mack, O., Khare, A., Krämer, A., \& Burgartz, T. (2015). Managing in a VUCA world. Basel: Springer.

*Mackenzie, C. S., Poulin, P. A., \& Seidman-Carlson, R. (2006). A brief mindfulness-based stress reduction intervention for nurses and nurse aides. Applied Nursing Research, 19(2), 105-109.

*Manotas, M., Segura, C., Eraso, M., Oggins, J., \& McGovern, K. (2014). Association of brief mindfulness training with reductions in perceived stress and distress in Colombian health care professionals. International Journal of Stress Management, 21(2), 207225.

Martin, A., Sanderson, K., \& Cocker, F. (2009). Meta-analysis of the effects of health promotion intervention in the workplace on depression and anxiety symptoms. Scandinavian Journal of Work, Environment \& Health, 35, 7-18.

*McConachie, D. A. J., McKenzie, K., Morris, P. G., \& Walley, R. M. (2014). Acceptance and mindfulness-based stress management for support staff caring for individuals with intellectual disabilities. Research in Developmental Disabilities, 35(1), 1216-1227.

Mesmer-Magnus, J., Manapragada, A., Viswesvaran, C., \& Allen, J. W. (2017). Trait mindfulness at work: a meta-analysis of the personal and professional correlates of trait mindfulness. Human Performance, 30(2-3), 79-98.

*Michel, A., Bosch, C., \& Rexroth, M. (2014). Mindfulness as a cognitive-emotional segmentation strategy: an intervention promoting work-life balance. Journal of Occupational and Organizational Psychology, 87(4), 733-754.

*Mistretta, E. G., Davis, M. C., Temkit, M. H., Lorenz, C., Darby, B., \& Stonnington, C. M. (2018). Resilience training for work-related stress among health care workers: results of a randomized clinical trial comparing in-person and smartphone-delivered interventions. Journal of Occupational and Environmental Medicine, 60(6), 559568.

Moher, D., Liberati, A., Tetzlaff, J., Altman, D. G., \& the Prisma Group. (2009). Preferred reporting items for systematic reviews and metaanalyses: the PRISMA statement. Annals of Internal Medicine, 151(4), 264-269.

*Molek-Winiarska, D., \& Żołnierczyk-Zreda, D. (2018). Application of mindfulness-based stress reduction to a stress management intervention in a study of a mining sector company. International Journal of Occupational Safety and Ergonomics, 24(4), 546-556.

Moll, S., Frolic, A., \& Key, B. (2015). Investing in compassion: exploring mindfulness as a strategy to enhance interpersonal relationships in healthcare practice. Journal of Hospital Administration, 4(6), 3645.

Morgan, P., Simpson, J., \& Smith, A. (2015). Health care workers' experiences of mindfulness training: a qualitative review. Mindfulness, 6(4), 744-758.

Mrazek, A. J., Mrazek, M. D., Cherolini, C. M., Cloughesy, J. N., Cynman, D. J., Gougis, L. J., et al. (2019). The future of mindfulness training is digital, and the future is now. Current Opinion in Psychology, 28, 81-86.

NBGH (2019). The employer investment in employee wellbeing. National Business Group on Health. https://www. businessgrouphealth.org/pub/?id=364D7F72-0162-0B77-D3B8ECA8468F4215. Accessed 18 Dec 2019.

Nübold, A., van Quaquebeke, N., \& Hülsheger, U. R. (2019). $\mathrm{Be}(\mathrm{com})$ ing real: a multi-source and an intervention study on mindfulness and authentic leadership. Journal of Business and Psychology. Epub ahead of print. DOI. https://doi.org/10.1007/ s10869-019-09633-y.

OECD (2018). GDP per hour worked (indicator). Organisation for economic co-operation and development. : https://www.oecd-ilibrary. org/economics/gdp-per-hour-worked/indicator/english 1439e590en . Accessed 12 Dec 2018.
Ostafin, B. D., \& Kassman, K. T. (2012). Stepping out of history: mindfulness improves insight problem solving. Consciousness and Cognition, 21(2), 1031-1036.

Parsons, C. E., Crane, C., Parsons, L. J., Fjorback, L. O., \& Kuyken, W. (2017). Home practice in mindfulness-based cognitive therapy and mindfulness-based stress reduction: a systematic review and metaanalysis of participants' mindfulness practice and its association with outcomes. Behaviour Research and Therapy, 95, 29-41.

Pinck, A. S., \& Sonnentag, S. (2017). Leader mindfulness and employee well-being: the mediating role of transformational leadership. Mindfulness, 9(3), 884-896.

Pincus, T., Miles, C., Froud, R., Underwood, M., Carnes, D., \& Taylor, S. J. (2011). Methodological criteria for the assessment of moderators in systematic reviews of randomised controlled trials: a consensus study. BMC Medical Research Methodology, 11(1), e14.

*Querstret, D., Cropley, M., \& Fife-Schaw, C. (2017). Internet-based instructor-led mindfulness for work-related rumination, fatigue, and sleep: Assessing facets of mindfulness as mechanisms of change a randomized waitlist control trial. Journal of Occupational Health Psychology, 22(2), 153-169.

Quick, J., \& Henderson, D. (2016). Occupational stress: preventing suffering, enhancing wellbeing. International Journal of Environmental Research and Public Health, 13(5), 459-470.

R Development Core Team. (2016). R: a language and environment for statistical computing. Vienna: R Foundation for Statistical Computing.

*Rao, M., Metri, K. G., Raghuram, N., \& Hongasandra, N. R. (2017). Effects of mind sound resonance technique (yogic relaxation) on psychological states, sleep quality, and cognitive functions in female Tteachers: a randomized, controlled trial. Advances in Mind-Body Medicine, 31(1), 4-9.

Raudenbush, S. W. (1994). Random effects models. In H. Coopers \& L. V. Hedges (Eds.), The handbook of research synthesis (pp. 301320). New York: Russell Sage Foundation.

Reb, J., Chaturvedi, S., Narayanan, J., \& Kudesia, R. S. (2019). Leader mindfulness and employee performance: a sequential mediation model of LMX quality, interpersonal justice, and employee stress. Journal of Business Ethics, 160(3), 745-763.

Reb, J., Narayanan, J., \& Ho, Z. W. (2015). Mindfulness at work: antecedents and consequences of employee awareness and absent-mindedness. Mindfulness, 6(1), 111-122.

*Rexroth, M., Michel, A., \& Bosch, C. (2017). Promoting well-being by teaching employees how to segment their life domains. Zeitschrift für Arbeits- und Organisationspsychologie, 61, 197-212.

*Roeser, R. W., Schonert-Reichl, K. A., Jha, A., Cullen, M., Wallace, L., Wilensky, R., et al. (2013). Mindfulness training and reductions in teacher stress and burnout: results from two randomized, waitlistcontrol field trials. Journal of Educational Psychology, 105(3), 787804.

Rudaz, M., Twohig, M. P., Ong, C. W., \& Levin, M. E. (2017). Mindfulness and acceptance-based trainings for fostering self-care and reducing stress in mental health professionals: a systematic review. Journal of Contextual Behavioral Science, 6(4), 380-390.

Ruiz-Canela, M., Martínez-González, M. A., \& Irala, J. (2000). Intention to treat analysis is related to methodological quality. $B M J, 320$, $1007-1008$.

Schaufenbuel, K. (2015). Why Google, Target, and General Mills are investing in mindfulness. Harvard Business Review. https:// mindleader.org/wp-content/uploads/2017/08/HARVARDBUSINESS-REVIEW Why-Google-is-investing-in-Mindfulness. pdf . Accessed 9 Sep 2019.

Schmidt, B., Schneider, M., Seeger, P., van Vianen, A., Loerbroks, A., \& Herr, R. M. (2019). A comparison of job stress models: associations with employee well-being, absenteeism, presenteeism, and resulting costs. Journal of Occupational and Environmental Medicine, 61(7), $535-544$. 
*Schroeder, D. A., Stephens, E., Colgan, D., Hunsinger, M., Rubin, D., \& Christopher, M. S. (2016). A brief mindfulness-based intervention for primary care physicians: a pilot randomized controlled trial. American Journal of Lifestyle Medicine, 12(1), 83-91.

Schuh, S. C., Zheng, M. X., Xin, K. R., \& Fernandez, J. A. (2019). The interpersonal benefits of leader mindfulness: a serial mediation model linking leader mindfulness, leader procedural justice enactment, and employee exhaustion and performance. Journal of Business Ethics, 156(4), 1007-1025.

Schumer, M. C., Lindsay, E. K., \& Creswell, J. D. (2018). Brief mindfulness training for negative affectivity: a systematic review and meta-analysis. Journal of Consulting and Clinical Psychology, 86(7), 569-583.

*Sheppard, W. D., Staggers, F. J., \& John, L. (1997). The effects of a stress management program in a high security government agency. Anxiety, Stress, \& Coping, 10(4), 341-350.

*Shonin, E., Van Gordon, W., Dunn, T. J., Singh, N. N., \& Griffiths, M. D. (2014). Meditation awareness training (MAT) for work-related wellbeing and job performance: a randomised controlled trial. International Journal of Mental Health and Addiction, 12(6), 806823.

*Singh, N. N., Lancioni, G. E., Medvedev, O. N., Myers, R. E., Chan, J., McPherson, C. L., et al. (2020). Comparative effectiveness of caregiver training in Mindfulness-Based Positive Behavior Support (MBPBS) and Positive Behavior Support (PBS) in a randomized controlled trial. Mindfulness, 11(1), 99-111.

Singh, S. K., \& Gorey, K. M. (2018). Relative effectiveness of mindfulness and cognitive behavioral interventions for anxiety disorders: meta-analytic review. Social Work in Mental Health, 16(2), 238251.

Slemp, G. R., Jach, H. K., Chia, A., Loton, D. J., \& Kern, M. L. (2019). Contemplative interventions and employee distress: a meta-analysis. Stress and Health, 35(3), 227-255.

*Slutsky, J., Chin, B., Raye, J., \& Creswell, J. D. (2018). Mindfulness training improves employee well-being: a randomized controlled trial. Journal of Occupational Health Psychology, 24(1), 139-149.

Smith, S. A. (2014). Mindfulness-based stress reduction: an intervention to enhance the effectiveness of nurses' coping with work-related stress. International Journal of Nursing Knowledge, 25(2), 119130.

*Song, Y., \& Lindquist, R. (2015). Effects of mindfulness-based stress reduction on depression, anxiety, stress and mindfulness in Korean nursing students. Nurse Education Today, 35(1), 86-90.

Spijkerman, M. P. J., Pots, W. T. M., \& Bohlmeijer, E. T. (2016). Effectiveness of online mindfulness-based interventions in improving mental health: a review and meta-analysis of randomised controlled trials. Clinical Psychology Review, 45, 102-114.

*Steinberg, B. A., Klatt, M., \& Duchemin, A. M. (2017). Feasibility of a mindfiilness-based intervention for surgical intensive care unit personnel. American Journal of Critical Care, 26(1), 10-18.

Sterne, J. A., Becker, B. J., \& Egger, M. (2005). The funnel plot. In H. R. Rothstein, A. J. Sutton, \& M. Borenstein (Eds.), Publication bias in meta-analysis: prevention, assessment and adjustments (pp. 75-98). Chichester: John Wiley \& Sons, Ltd.

Strauss, C., Cavanagh, K., Oliver, A., \& Pettman, D. (2014). Mindfulness-based interventions for people diagnosed with a current episode of an anxiety or depressive disorder: a meta-analysis of randomised controlled trials. PLoS One, 9(4), e96110.

Strömberg, C., Aboagye, E., Hagberg, J., Bergström, G., \& LohelaKarlsson, M. (2017). Estimating the effect and economic impact of absenteeism, presenteeism, and work environment-related problems on reductions in productivity from a managerial perspective. Value in Health, 20(8), 1058-1064.

*Strub, L., \& Tarquinio, C. (2013). Mindfulness-based cognitive therapy (MBCT) program with workers in an industrial setting: a pilot study. Sante Mentale au Quebec, 38(1), 207-225.
Sutcliffe, K. M., Vogus, T. J., \& Dane, E. (2016). Mindfulness in organizations: a cross-level review. Annual Review of Organizational Psychology and Organizational Behavior, 3, 55-81.

*Tagg, R. (2016). Decreasing stress in paraprofessionals working with children with autism using a brief, blended mindfulness intervention. Doctoral Dissertation, Alliant International University, San Diego.

Tang, Y. Y., Hölzel, B. K., \& Posner, M. I. (2015). The neuroscience of mindfulness meditation. Nature Reviews Neuroscience, 16(4), 213-225.

*Taylor, C., Harrison, J., Haimovitz, K., Oberle, E., Thomson, K., Schonert-Reichl, K., et al. (2016). Examining ways that a mindfulness-based intervention reduces stress in public school teachers: a mixed-methods study. Mindfulness, 7(1), 115-129.

Trowbridge, K., \& Mische Lawson, L. (2016). Mindfulness-based interventions with social workers and the potential for enhanced patientcentered care: a systematic review of the literature. Social Work in Health Care, 55(2), 101-124.

*Valley, M. A., \& Stallones, L. (2017). Effect of mindfulness-based stress reduction training on health care worker safety: a randomized waitlist controlled trial. Journal of Occupational and Environmental Medicine, 59(10), 935-941.

*van Berkel, J., Boot, C. R., Proper, K. I., Bongers, P. M., \& van der Beek, A. J. (2014). Effectiveness of a worksite mindfulness-based multi-component intervention on lifestyle behaviors. International Journal of Behavioral Nutrition and Physical Activity, 11(1), 9, https://doi.org/10.1186/1479-5868-11-9 .

Van Dam, N. T., van Vugt, M. K., Vago, D. R., Schmalzl, L., Saron, C. D., Olendzki, A., et al. (2018). Mind the hype: a critical evaluation and prescriptive agenda for research on mindfulness and meditation. Perspectives on Psychological Science, 13(1), 36-61.

*Verweij, H., van Ravesteijn, H., van Hooff, M. L. M., Lagro-Janssen, A. L. M., \& Speckens, A. E. M. (2018). Mindfulness-based stress reduction for residents: a randomized controlled trial. Journal of General Internal Medicine, 33(4), 429-436.

Viechtbauer, W. (2005). Bias and efficiency of meta-analytic variance estimators in the random-effects model. Journal of Educational and Behavioral Statistics, 30(3), 261-293.

Viechtbauer, W. (2010). Conducting meta-analyses in R with the metafor package. Journal of Statistical Software, 36(3), 1-48.

Viechtbauer, W., \& Cheung, M. W. L. (2010). Outlier and influence diagnostics for meta-analysis. Research Synthesis Methods, 1(2), $112-125$.

Virgili, M. (2015). Mindfulness-based interventions reduce psychological distress in working adults: a meta-analysis of intervention studies. Mindfulness, 6(2), 326-337.

*Wilson, D. M. (2012). Effects of mindfulness-based art processing $(M B A P)$ on the well-being and job performance of working adults: evaluating a novel intervention. Doctoral Dissertation, Sofia University, Paolo Alto.

*Wolever, R. Q., Bobinet, K. J., McCabe, K., Mackenzie, E. R., Fekete, E., Kusnick, C. A., et al. (2012). Effective and viable mind-body stress reduction in the workplace: a randomized controlled trial. Journal of Occupational Health Psychology, 17(2), 246-258.

Wolever, R. Q., Schwartz, E. R., \& Schoenberg, P. L. (2018). Mindfulness in corporate America: is the Trojan horse ethical? The Journal of Alternative and Complementary Medicine, 24(5), 403-406.

*Yang, J., Tang, S., \& Zhou, W. (2018). Effect of mindfulness-based stress reduction therapy on work stress and mental health of psychiatric nurses. Psychiatria Danubina, 30(2), 189-196.

*Żołnierczyk-Zreda, D., Sanderson, M., \& Bedyńska, S. (2016). Mindfulness-based stress reduction for managers: a randomized controlled study. Occupational Medicine, 66(8), 630-635.

Publisher's Note Springer Nature remains neutral with regard to jurisdictional claims in published maps and institutional affiliations. 